\title{
5-Oxo-hexahydroquinoline Derivatives and Their Tetrahydroquinoline Counterparts as Multidrug Resistance Reversal Agents
}

\author{
Omolbanin Shahraki ${ }^{1,2}$, Mehdi Khoshneviszadeh ${ }^{2,3}$, Mojtaba Dehghani ${ }^{2,3}$, \\ Maryam Mohabbati ${ }^{2}$, Marjan Tavakkoli ${ }^{2}$, Luciano Saso ${ }^{4}$, Najmeh Edraki ${ }^{2, *}$ and \\ Omidreza Firuzi $2, *$ \\ 1 Cellular and Molecular Research Center, Resistant Tuberculosis Institute, Zahedan University of Medical \\ Sciences, Zahedan 98167-43463, Iran; o.shahraki@gmail.com \\ 2 Medicinal and Natural Products Chemistry Research Center, Shiraz University of Medical Sciences, \\ Shiraz 71348-53734, Iran; m.khoshneviszadeh@gmail.com (M.K.); Dehghanimojtaba58@yahoo.com (M.D.); \\ m_mohabati2000@yahoo.com (M.M.); tavakkoli_marjan@yahoo.com (M.T.) \\ 3 Department of Medicinal Chemistry, Faculty of Pharmacy, Shiraz University of Medical Sciences, \\ Shiraz 71468-64685, Iran \\ 4 Department of Physiology and Pharmacology "Vittorio Erspamer", Sapienza University of Rome, \\ P. le Aldo Moro 5, 00185 Rome, Italy; luciano.saso@uniroma1.it \\ * Correspondence: edrakin@sums.ac.ir (N.E.); firuzio@sums.ac.ir (O.F.); Tel.: +98-71-3230-7869 (N.E.); \\ +98-71-3230-3872 (O.F.)
}

Received: 9 February 2020; Accepted: 31 March 2020; Published: 16 April 2020

\begin{abstract}
Cancer is a leading cause of death worldwide. Multidrug resistance (MDR) is a main reason of chemotherapy failure in many patients and is often related to overexpression of ATP-binding cassette $(\mathrm{ABC})$ transporters, including P-glycoprotein (P-gp/ABCB1). Agents that are capable of modulation of the activity of these transporters might be effective in overcoming MDR. In this study, a new set of 1,4,5,6,7,8-hexahydro 5-oxo quinoline-3-carboxamide derivatives bearing 4-methylthiazole moiety and their tetrahydroquinoline counterparts were synthesized. MDR reversal activity of these 16 newly synthesized derivatives was tested in P-gp overexpressing MES-SA-DX5 human uterine sarcoma cells by flow cytometric determination of Rhodamine123 efflux. The effect of the most potent compounds in induction of apoptosis and alterations of cell cycle was examined in these cells by a flow cytometric method. Inherent cytotoxicity of the synthesized compounds was evaluated against MCF-7, A-549 and K562 cancer cell lines, as well as MES-SA-DX5 and their parental non-resistant MES-SA and also HEK-293 non-cancerous cells by MTT assay. Compounds A1 and A2 with 5-oxo-hexahydroquinoline structure bearing 2,4-dichlorophenyl and 4-bromophenyl moieties, respectively, and their tetrahydroquinoline counterparts B1 and B2 significantly blocked P-gp efflux, induced apoptosis and showed the highest cytotoxicities against MES-SA-DX5 cells. However, only A2 and B2 compounds were relatively selective against cancer and MDR cells as compared to non-resistant and non-cancerous cells. These findings demonstrate that 5-oxo-hexahydroquinoline and 5-oxo-tetrahydroquinoline derivatives represent promising agents with therapeutic potential in drug resistant cancers.
\end{abstract}

Keywords: anticancer drug resistance; efflux pumps; antiproliferative agents; drug design; 1,4-dihydropyridine

\section{Introduction}

Cancer is a major cause of death and disability worldwide and despite considerable diagnostic and therapeutic advancements in recent years, it is still the cause of more than 8 million deaths in the world 
every year [1]. The resistance of malignant tumor cells to multiple structurally and mechanistically unrelated classes of anticancer agents is recognized as multidrug resistance (MDR). This phenomenon very often occurs in advanced cancer cases and is a major cause of failure of therapies [2,3]. Different mechanisms are involved in MDR: Very often it is caused by the overexpression of P-glycoprotein (P-gp), also named multidrug resistance protein-1 (MDR1), which is encoded by ATP-binding cassette $(A B C)$ subfamily B member 1 (ABCB1) gene [4]. P-gp has been one of the first members of $A B C$ transporters to be studied [5]. It functions as an efflux pump extruding several substrate molecules and plays an important physiological role in cleaning cells from xenobiotics and maintaining the integrity of blood-brain barrier [6]. However, overexpression of P-gp in cancer cells leads to reduced accumulation of cytotoxic drugs and even targeted therapeutics resulting in resistance against these agents [3,7].

In this context, targeting P-gp by small-molecule inhibitors seems to be a promising approach for overcoming MDR and restoring chemosensitivity in tumor cells [4]. In spite of numerous considerable efforts using different classes of compounds, there is no approved MDR-targeting drug available yet $[3,8,9]$. Hence, new P-gp inhibitors with high potency and selectivity are much needed to be developed.

One important class of candidate compounds capable of MDR reversal, is 1,4-dihydropyridine derivatives. 1,4-DHPs possess several important pharmacological properties including calcium-channel-blocking, bronchodilator, anti-ischemic and antitumor as well as MDR reversal effects [10-15]. Several agents structurally related to 1,4-DHP derivatives have been reported as P-gp inhibitors [16-21].

We have recently designed and synthesized a set of 5-oxohexahydroquinoline [22] and tetrahydroquinolinone derivatives [20] closely related structures to 1,4-DHPs, as MDR reversal agents. Here, in another attempt to respond to the crucial need for novel cancer therapeutic agents and as part of our research program toward the discovery of useful MDR reversal compounds, we report the synthesis and biological evaluation a set of sixteen 5-oxo-hexahydroquinoline derivatives. The findings of the study showed that some of these compounds are capable of reversing MDR in P-gp overexpressing cancer cells.

\section{Materials and Methods}

\subsection{Chemistry}

All the reagents were bought from Sigma Aldrich chemical Co. or Merck and used without further purification. Melting points were recorded by a hot stage apparatus (Electrothermal, Essex, UK) and reported without correction. ${ }^{1} \mathrm{H}-\mathrm{NMR}$ spectra were determined by a Bruker FT-400 MHz spectrometer (Bruker Daltonics, Bremen, Germany) in DMSO-d6. All the chemical shifts were reported as (d) values (ppm) against tetramethylsilane as an internal standard. The MS spectra were recorded using an Agilent 7890A spectrometer at $70 \mathrm{eV}$. Elemental analyses were performed on a TESCAN-Vega3 CNO analyzer (TESCAN, Brno, Czech Republic).

General Procedure of the Synthesis

2-Methylthiazol-4-amine (5 mmol) was mixed with 2,2,6-trimethyl-4H-1,3-dioxin-4-one (6 mmol) in $10 \mathrm{~mL}$ xylene. The mixture was refluxed for $2-4 \mathrm{~h}$. The reaction procedure was monitored using TLC (thin layer chromatography). At the end of reaction, the precipitate was removed and washed with petroleum ether (30-50 mL). The obtained product, $\mathrm{N}$-(2-methylthiazol-4-yl)-3-oxobutanamide, cyclohexane-1,3-dione and different aryl aldehydes were mixed in equimolar and excess amount of ammonium acetate was added. The mixture was refluxed in ethanol for $24 \mathrm{~h}$. The oxidized products were achieved with high purity via oxidation for $24-48 \mathrm{~h}$ in the presence of $\mathrm{MnO}_{2}$ and ethanol as solvent. The acquired products of each step were characterized using ${ }^{1} \mathrm{H}-\mathrm{NMR},{ }^{13} \mathrm{C}-\mathrm{NMR}$, mass and IR spectroscopy. All spectra are shown in Figures S1-S64, Supplementary Materials. 
N-(2-Methylthiazol-4-yl)-3-oxobutanamide (a): Yield: 86\%, yellow powder, mp: $173-175{ }^{\circ} \mathrm{C},{ }^{1} \mathrm{H}-\mathrm{NMR}$ (DMSO-d6) $\delta: 11.65(1 \mathrm{H}$, brs, amide $\mathrm{N}-\mathrm{H}), 7.26\left(1 \mathrm{H}\right.$, Apparent s, thiazole $\left.\mathrm{C}_{5}-\mathrm{H}\right), 3.76\left(2 \mathrm{H}, \mathrm{s}, \mathrm{COCH}_{2} \mathrm{CO}\right)$, $2.35\left(3 \mathrm{H}, \mathrm{s}, \mathrm{CH}_{3} \mathrm{CO}\right), 2.21\left(3 \mathrm{H}\right.$, Apparent, thiazole- $\left.\mathrm{CH}_{3}\right) ; \mathrm{IR}(\mathrm{KBr}) \vee\left(\mathrm{cm}^{-1}\right): 3179(\mathrm{~N}-\mathrm{H}$, amide), 3053 (C-H, aromatic), 2974, 2899 ( $\mathrm{C}-\mathrm{H}$, aliphatic), 1723 (C=O, ketone), 1672 (C=O, amide); MS m/z (\%): 198(29) [M+], 141(8), 114(100), 72(23), 43(65).

4-(2,4-Dichlorophenyl)-2-methyl-N-(2-methylthiazol-4-yl)-5-oxo-1,4,5,6,7,8-hexahydroquinoline-3-carboxamide (A1): Yield 95\%; yellow powder; mp. $195{ }^{\circ} \mathrm{C} ;{ }^{1} \mathrm{H}-\mathrm{NMR}\left(500 \mathrm{MHz}, \mathrm{DMSO}-\mathrm{d}_{6}\right) \delta: 11.92(\mathrm{~s}, 1 \mathrm{H}$, amide $\mathrm{N}-\mathrm{H}), 8.95(\mathrm{~s}, 1 \mathrm{H}, \mathrm{NH}-\mathrm{DHP}), 7.33\left(\mathrm{~d}, 1 \mathrm{H}, J=2.0 \mathrm{~Hz}, \mathrm{C}_{3}-\mathrm{H}\right), 7.30\left(\mathrm{~d}, 1 \mathrm{H}, J=8.5 \mathrm{~Hz}, \mathrm{C}_{5}-\mathrm{H}\right), 7.23(\mathrm{~d}, 1 \mathrm{H}, J$ $\left.=8.5 \mathrm{~Hz}, \mathrm{C}_{6}-\mathrm{H}\right), 6.67\left(\mathrm{~s}, 1 \mathrm{H}\right.$, thiazole-H), $5.35\left(\mathrm{~s}, 1 \mathrm{H}, \mathrm{DHP} \mathrm{C}_{4}-\mathrm{H}\right), 2.23\left(\mathrm{~s}, 3 \mathrm{H}\right.$, thiazole- $\left.\mathrm{CH}_{3}\right), 2.21-2.09$ $\left(\mathrm{m}, 2 \mathrm{H}\right.$, cyclohexanone $\left.\mathrm{C}_{6}-\mathrm{H}\right), 1.93\left(\mathrm{~s}, 3 \mathrm{H}, \mathrm{DHP}-\mathrm{CH}_{3}\right), 1.91-1.79\left(\mathrm{~m}, 2 \mathrm{H}\right.$, cyclohexanone $\left.\mathrm{C}_{8}-\mathrm{H}\right), 1.82-1.80$ (m, 2H, cyclohexanone $\left.\mathrm{C}_{7}-\mathrm{H}\right) .{ }^{13} \mathrm{C}-\mathrm{NMR}\left(125 \mathrm{MHz}, \mathrm{DMSO}-\mathrm{d}_{6}\right)$ : 194.19, 153.37, 144.15, 136.18, 132.67, 132.61. 131.38, 128.45, 127.89, 109.25, 108.61. 107.78, 37.18, 36.03, 26.84, 25.01, 21.52, 21.36, 19.02, 17.36, 17.12. IR (KBr) v ( $\left.\mathrm{cm}^{-1}\right)$ : 3197 (DHP N-H), 3080 (C-H, aromatic), 2947 (C-H, aliphatic), 1675, 1608 (C=O, amide, ketone); MS m/z (\%): 449 (30) [M + 2] $]^{+}, 448$ (8) [M + 1] $]^{+}, 447$ (22) [M], 412 (19), 334 (100), 298 (16), 272 (28), 162 (35), 115 (29), Anal. Calcd: C, 56.26; N, 9.37; O, 7.14. Found: C, 56.19; N, 9.25; O, 7.09.

4-(4-Bromophenyl)-2-methyl-N-(2-methylthiazol-4-yl)-5-oxo-1,4,5,6,7,8-hexahydroquinoline-3-carboxamide (A2): Yield 92\%; yellow powder; mp. $273{ }^{\circ} \mathrm{C} ;{ }^{1} \mathrm{H}-\mathrm{NMR}\left(500 \mathrm{MHz}, \mathrm{DMSO}-d_{6}\right) \delta: 11.80(\mathrm{~s}, 1 \mathrm{H}$, amide $\mathrm{N}-\mathrm{H}), 8.97(\mathrm{~s}, 1 \mathrm{H}, \mathrm{NH}-\mathrm{DHP}), 7.38\left(\mathrm{~d}, 2 \mathrm{H}, J=8.5 \mathrm{~Hz}, \mathrm{C}_{3}-\mathrm{H}, \mathrm{C}_{5}-\mathrm{H}\right), 7.13\left(\mathrm{~d}, 2 \mathrm{H}, J=8.5 \mathrm{~Hz}, \mathrm{C}_{2}-\mathrm{H}_{1} \mathrm{C}_{6}-\mathrm{H}\right)$, $6.66\left(\mathrm{~s}, 1 \mathrm{H}\right.$, thiazole-H), $5.08\left(\mathrm{~s}, 1 \mathrm{H}, \mathrm{DHP}_{4}-\mathrm{H}\right), 2.48-2.46\left(\mathrm{~m}, 2 \mathrm{H}\right.$, cyclohexanone $\left.\mathrm{C}_{8}-\mathrm{H}\right), 2.24(\mathrm{~s}, 3 \mathrm{H}$, thiazole- $\left.\mathrm{CH}_{3}\right), 2.20-2.14\left(\mathrm{~m}, 2 \mathrm{H}\right.$, cyclohexanone $\left.\mathrm{C}_{6}-\mathrm{H}\right), 2.10\left(\mathrm{~s}, 3 \mathrm{H}, \mathrm{DHP}-\mathrm{CH}_{3}\right), 1.92-1.72(2 \times \mathrm{m}, 2 \mathrm{H}$, cyclohexanone $\left.\mathrm{C}_{7}-\mathrm{H}\right) .{ }^{13} \mathrm{C}-\mathrm{NMR}\left(125 \mathrm{MHz}, \mathrm{DMSO}_{\mathrm{d}}\right.$ ): 194.59, 152.46, 146.72, 138.75, 131.30, 130.19, 119.37, 109.89, 107.92, 107.88, 107.83, 56.49, 37.40, 37.20, 26.75, 21.24, 19.02, 17.72, 17.30. IR (KBr) v ( $\left.\mathrm{cm}^{-1}\right)$ : 3191 (DHP N-H), 3055 (C-H, aromatic), 2945 (C-H, aliphatic), 1667, 1607 (C=O, amide, ketone) ; MS m/z (\%): 459 (34) [M + 2] $]^{+}, 457$ (34) [M], 346 (74), 344 (80), 317 (34), 300 (26), 264 (19), 162 (100), Anal. Calcd: C, 55.03; N, 9.17; O, 6.98. Found: C, 54.99; N, 9.03; O, 6.73.

4-(3-Chlorophenyl)-2-methyl-N-(2-methylthiazol-4-yl)-5-oxo-1,4,5,6,7,8-hexahydroquinoline-3-carboxamide (A3): Yield 88\%; yellow powder; mp. $253{ }^{\circ} \mathrm{C} ;{ }^{1} \mathrm{H}-\mathrm{NMR}\left(500 \mathrm{MHz}, \mathrm{DMSO}-d_{6}\right) \delta: 11.83(\mathrm{~s}, 1 \mathrm{H}$, amide $\mathrm{N}-\mathrm{H}), 9.00(\mathrm{~s}, 1 \mathrm{H}, \mathrm{NH}-\mathrm{DHP}), 7.22\left(\mathrm{t}, 1 \mathrm{H}, J=8.0 \mathrm{~Hz}, \mathrm{C}_{4}-\mathrm{H}\right), 7.18\left(\mathrm{~s}, 1 \mathrm{H}, \mathrm{C}_{2}-\mathrm{H}\right), 7.14(\mathrm{t}, 2 \mathrm{H}, J=6.0 \mathrm{~Hz}$, $\left.\mathrm{C}_{5}-\mathrm{H}, \mathrm{C}_{6}-\mathrm{H}\right), 6.67\left(\mathrm{~s}, 1 \mathrm{H}\right.$, thiazole-H), $5.12\left(\mathrm{~s}, 1 \mathrm{H}\right.$, DHP $\left.\mathrm{C}_{4}-\mathrm{H}\right), 2.48-2.47\left(\mathrm{~m}, 2 \mathrm{H}\right.$, cyclohexanone $\left.\mathrm{C}_{8}-\mathrm{H}\right)$, $2.23\left(\mathrm{~s}, 3 \mathrm{H}\right.$, thiazole- $\left.\mathrm{CH}_{3}\right), 2.21-2.17\left(\mathrm{~m}, 2 \mathrm{H}\right.$, cyclohexanone $\left.\mathrm{C}_{6}-\mathrm{H}\right), 2.13\left(\mathrm{~s}, 3 \mathrm{H}, \mathrm{DHP}-\mathrm{CH}_{3}\right), 1.92-1.74(2$ $\times \mathrm{m}, 2 \mathrm{H}$, cyclohexanone $\left.\mathrm{C}_{7}-\mathrm{H}\right) .{ }^{13} \mathrm{C}-\mathrm{NMR}\left(125 \mathrm{MHz}, \mathrm{DMSO}-d_{6}\right): 194.65,152.63,149.69,139.02,139.00$, 137.63, 133.10, 130.32, 127.74, 126.69, 126.30, 109.73, 107.70, 56.49, 37.65, 37.17, 26.75, 21.22, 19.01, 17.77, 17.27. IR (KBr) v (cm $\left.{ }^{-1}\right): 3189$ (DHP N-H), 3065 (C-H, aromatic), 2970 (C-H, aliphatic), 1670, 1604 (C=O, amide, ketone), 1548, 1378 (C-NO 2 aromatic); $\mathrm{MS} \mathrm{m/z} \mathrm{( \% ):} 415$ (21) [M + 2] $]^{+}, 413$ (51) [M], 302 (47), 300 (100), 264 (36), 115 (37), Anal. Calcd: C, 60.94; N, 10.15; O, 7.73. Found: C, 60.82; N, 10.08; O, 7.46.

2-Methyl-N-(2-methylthiazol-4-yl)-5-oxo-4-(3,4,5-trimethoxyphenyl)-1,4,5,6,7,8-hexahydroquinoline-3-carboxamide (A4): Yield 81\%; yellow powder; mp. $160{ }^{\circ} \mathrm{C} ;{ }^{1} \mathrm{H}-\mathrm{NMR}\left(500 \mathrm{MHz}, \mathrm{DMSO}-\mathrm{d}_{6}\right)$ 8: 8.99 (s, 1H, NH-DHP), $6.67\left(\mathrm{~s}, 1 \mathrm{H}\right.$, thiazole-H), $6.41\left(\mathrm{~s}, 2 \mathrm{H}, \mathrm{C}_{2}-\mathrm{H}, \mathrm{C}_{6}-\mathrm{H}\right), 5.09\left(\mathrm{~s}, 1 \mathrm{H}, \mathrm{DHP} \mathrm{C}_{4}-\mathrm{H}\right), 3.62\left(\mathrm{~s}, 6 \mathrm{H},-\mathrm{OCH}_{3}\right), 3.57(\mathrm{~s}$, $\left.3 \mathrm{H},-\mathrm{OCH}_{3}\right), 2.56-2.51\left(\mathrm{~m}, 3 \mathrm{H}\right.$, thiazole- $\left.\mathrm{CH}_{3}\right), 2.26-2.23\left(\mathrm{~m}, 5 \mathrm{H}\right.$, cyclohexanone $\mathrm{C}_{6}-\mathrm{H}$, cyclohexanone $\left.\mathrm{C}_{8}-\mathrm{H}\right), 2.09$ (s, 3H, DHP-CH $\left.\mathrm{CH}_{3}\right), 1.96-1.81\left(2 \times \mathrm{m}, 2 \mathrm{H}\right.$, cyclohexanone $\left.\mathrm{C}_{7}-\mathrm{H}\right) .{ }^{13} \mathrm{C}-\mathrm{NMR}(125 \mathrm{MHz}$, DMSO- $\left.d_{6}\right)$ : $194.77,167.75,152.91,162.67,146.76,143.03,138.06,136.05,109.52,108.65,107.67,104.78$, $60.25,56.48,55.95,37.74,37.34,26.83,21.42,19.01,17.67,17.30 . \mathrm{IR}(\mathrm{KBr}) \vee\left(\mathrm{cm}^{-1}\right): 3305(\mathrm{DHP} \mathrm{N}-\mathrm{H})$, 2932 (C-H, aromatic), 2895 (C-H, aliphatic), 1609 (C=O, amide, ketone), 1267, 1002 (C-O, aromatic); MS m/z (\%): 469 (19) [M] $]^{+}, 356$ (34), 324 (20), 300 (15), 218 (16), 170 (18), 156 (100), Anal. Calcd: C, 61.39, N, 8.95; O, 17.04. Found: C, 61.28; N, 8.75; O, 16.94 .

4-(4-Chlorophenyl)-2-methyl-N-(2-methylthiazol-4-yl)-5-oxo-1,4,5,6,7,8-hexahydroquinoline-3-carboxamide (A5): Yield 90\%; yellow powder; mp. $253{ }^{\circ} \mathrm{C} ;{ }^{1} \mathrm{H}-\mathrm{NMR}\left(500 \mathrm{MHz}, \mathrm{DMSO}-d_{6}\right) \delta: 11.79(\mathrm{~s}, 1 \mathrm{H}$, amide $\mathrm{N}-\mathrm{H}), 8.97(\mathrm{~s}, 1 \mathrm{H}, \mathrm{NH}-\mathrm{DHP}), 7.24\left(\mathrm{~d}, 2 \mathrm{H}, \mathrm{J}=8.0 \mathrm{~Hz}, \mathrm{C}_{3}-\mathrm{H}, \mathrm{C}_{5}-\mathrm{H}\right), 7.18\left(\mathrm{~d}, 2 \mathrm{H}, J=8.0 \mathrm{~Hz}, \mathrm{C}_{2^{-}}, \mathrm{C}_{6}-\mathrm{H}\right)$, 
$6.67\left(\mathrm{~s}, 1 \mathrm{H}\right.$, thiazole-H), $5.09\left(\mathrm{~s}, 1 \mathrm{H}, \mathrm{DHP} \mathrm{C}_{4}-\mathrm{H}\right), 2.48-2.46\left(\mathrm{~m}, 2 \mathrm{H}\right.$, cyclohexanone $\left.\mathrm{C}_{8}-\mathrm{H}\right), 2.23(\mathrm{~s}, 3 \mathrm{H}$, thiazole- $\left.\mathrm{CH}_{3}\right), 2.23-2.14\left(\mathrm{~m}, 2 \mathrm{H}\right.$, cyclohexanone $\left.\mathrm{C}_{8}-\mathrm{H}\right), 2.10\left(\mathrm{~s}, 3 \mathrm{H}, \mathrm{DHP}_{-} \mathrm{CH}_{3}\right), 1.92-1.75(2 \times \mathrm{m}, 2 \mathrm{H}$, cyclohexanone $\left.\mathrm{C}_{7}-\mathrm{H}\right) .{ }^{13} \mathrm{C}-\mathrm{NMR}\left(125 \mathrm{MHz}\right.$, DMSO- $\left.d_{6}\right)$ : 194.68, 172.20, 152.45, 139.28, 130.82, 129.76, $128.38,123.93,109.94,43.70,43.68,42.70,38.94,37.20,26.75,21.24,17.72,17.05 . \mathrm{IR}(\mathrm{KBr}) \vee\left(\mathrm{cm}^{-1}\right): 3269$ (DHP N-H), 3195 (C-H, aromatic), 2956 (C-H, aliphatic), 1667, 1608 (C=O, amide, ketone); MS m/z (\%): 415 (10) $[\mathrm{M}+2]^{+}, 413(3)[\mathrm{M}]^{+}, 300$ (44), 298 (100), 267 (30), 239 (39), Anal. Calcd: C, 60.94; N, 10.15; O, 7.73. Found: $\mathrm{C}, 60.86 ; \mathrm{N}, 10.04 ; \mathrm{O}, 7.41$.

4-(3-Ethoxy-4-hydroxyphenyl)-2-methyl-N-(2-methylthiazol-4-yl)-5-oxo-1,4,5,6,7,8-hexahydroquinoline-3-carboxamide (A6): Yield 85\%; yellow powder; mp. $251{ }^{\circ} \mathrm{C} ;{ }^{1} \mathrm{H}-\mathrm{NMR}\left(500 \mathrm{MHz}, \mathrm{DMSO}-d_{6}\right) \delta: 11.63(\mathrm{~s}, 1 \mathrm{H}$, amide $\mathrm{N}-\mathrm{H}), 8.85(\mathrm{~s}, 1 \mathrm{H}, \mathrm{NH}-\mathrm{DHP}), 8.56(\mathrm{~s}, 1 \mathrm{H}, \mathrm{OH}), 6.71\left(\mathrm{~s}, 1 \mathrm{H}, \mathrm{C}_{2}-\mathrm{H}\right), 6.62(\mathrm{~s}, 1 \mathrm{H}$, thiazole-H), $6.59(\mathrm{~d}, 1 \mathrm{H}, J$ $\left.=8.0 \mathrm{~Hz}, \mathrm{C}_{5}-\mathrm{H}\right), 6.52\left(\mathrm{~d}, 1 \mathrm{H}, J=8.0 \mathrm{~Hz}, \mathrm{C}_{6}-\mathrm{H}\right), 4.98\left(\mathrm{~s}, 1 \mathrm{H}, \mathrm{DHPC}_{4}-\mathrm{H}\right), 3.91-3.76\left(\mathrm{~m}, 2 \mathrm{H}, \mathrm{CH}_{3}-\mathrm{CH}_{2}-\mathrm{O}\right)$, 2.48-2.45 (m, 2H, cyclohexanone $\left.\mathrm{C}_{8}-\mathrm{H}\right), 2.24-2.19\left(\mathrm{~m}, 5 \mathrm{H}\right.$, cyclohexanone $\mathrm{C}_{6}-\mathrm{H}$, thiazole- $\left.\mathrm{CH}_{3}\right), 2.09$ (s, 3H, DHP- $\left.\mathrm{CH}_{3}\right), 1.93-1.78\left(2 \times \mathrm{m}, 2 \mathrm{H}\right.$, cyclohexanone $\left.\mathrm{C}_{7}-\mathrm{H}\right) .1 .23\left(\mathrm{t}, 3 \mathrm{H}, \mathrm{J}=7.0, \mathrm{CH}_{3}-\mathrm{CH}_{2}-\mathrm{O}\right) .{ }^{13} \mathrm{C}-\mathrm{NMR}$ $\left(125 \mathrm{MHz}\right.$, DMSO- $\left.d_{6}\right): 194.66,167.45,155.99,151.91,146.97,146.38,145.36,138.58,138.29,119.98,115.64$, 113.70, 110.50, 108.62, 107.73, 64.04, 37.34, 36.97, 26.79, 21.35, 17.70, 17.37, 15.12. (IR (KBr) $v\left(\mathrm{~cm}^{-1}\right)$ : 3282 (DHP N-H), 3067 (C-H, aromatic), 2990 (C-H, aliphatic), 1666, 1614 (C=O, amide, ketone); MS m/z (\%): 439 (1) [M] $]^{+}, 310$ (10), 285 (57), 268 (14), 162 (100), Anal. Calcd: C, 62.85; N, 9.56; O, 14.56. Found: C, $62.45 ; \mathrm{N}, 9.32 ; \mathrm{O}, 14.18$.

4-(4-Methoxyphenyl)-2-methyl-N-(2-methylthiazol-4-yl)-5-oxo-1,4,5,6,7,8-hexahydroquinoline-3-carboxamide (A7): Yield 78\%; yellow powder; mp. $185^{\circ} \mathrm{C} ;{ }^{1} \mathrm{H}-\mathrm{NMR}\left(500 \mathrm{MHz}, \mathrm{DMSO}-\mathrm{d}_{6}\right) \delta: 11.82(\mathrm{~s}, 1 \mathrm{H}$, amide $\mathrm{N}-\mathrm{H}), 8.89$ (s, 1H, NH-DHP), $7.08\left(\mathrm{~d}, 2 \mathrm{H}, J=8.0 \mathrm{~Hz}, \mathrm{C}_{5}-\mathrm{H}, \mathrm{C}_{3}-\mathrm{H}\right), 6.74\left(\mathrm{~d}, 2 \mathrm{H}, J=8.0 \mathrm{~Hz}, \mathrm{C}_{2}-\mathrm{H}_{1} \mathrm{C}_{6}-\mathrm{H}\right)$, $6.66\left(\mathrm{~s}, 1 \mathrm{H}\right.$, thiazole-H), $5.04\left(\mathrm{~s}, 1 \mathrm{H}, \mathrm{DHP} \mathrm{C}_{4}-\mathrm{H}\right), 3.66\left(\mathrm{~s}, 3 \mathrm{H}, \mathrm{CH}_{3}-\mathrm{O}\right), 2.47-2.44(\mathrm{~m}, 2 \mathrm{H}$, cyclohexanone $\left.\mathrm{C}_{8}-\mathrm{H}\right), 2.23-2.17\left(\mathrm{~m}, 5 \mathrm{H}\right.$, cyclohexanone $\mathrm{C}_{6}-\mathrm{H}$, thiazole- $\left.\mathrm{CH}_{3}\right), 2.10\left(\mathrm{~s}, 3 \mathrm{H}, \mathrm{DHP}-\mathrm{CH}_{3}\right), 1.91-1.72(2 \times \mathrm{m}$, $2 \mathrm{H}$, cyclohexanone $\left.\mathrm{C}_{7}-\mathrm{H}\right) .{ }^{13} \mathrm{C}-\mathrm{NMR}\left(125 \mathrm{MHz}, \mathrm{DMSO}-d_{6}\right)$ : $194.56,172.48,157.83,151.89,139.72,139.67$, 138.54, 128.88, 113.81, 110.68, 108.51, 107.69, 55.31, 37.28, 36.74, 26.76, 21.52, 21.29, 17.71, 17.31. (IR $(\mathrm{KBr}) \vee\left(\mathrm{cm}^{-1}\right): 3196(\mathrm{DHP} \mathrm{N}-\mathrm{H}), 3076(\mathrm{C}-\mathrm{H}$, aromatic), 2943 (C-H, aliphatic), 1675, 1608 (C=O, amide, ketone); MS m/z (\%): 407 (15) [M - 2] $]^{+}, 294$ (100), 251 (5), 223 (4), Anal. Calcd: C, 64.53; N, 10.26; O, 11.72. Found: $\mathrm{C}, 64.41 ; \mathrm{N}, 10.20 ; \mathrm{O}, 11.58$.

4-(3,4-Dimethoxyphenyl)-2-methyl-N-(2-methylthiazol-4-yl)-5-oxo-1,4,5,6,7,8-hexahydroquinoline-3-carboxamide (A8): Yield 73\%; yellow powder; mp. $222{ }^{\circ} \mathrm{C} ;{ }^{1} \mathrm{H}-\mathrm{NMR}\left(500 \mathrm{MHz}, \mathrm{DMSO}-d_{6}\right) \delta$ : 11.69 (s, $1 \mathrm{H}$, amide $\mathrm{N}-\mathrm{H}), 8.88(\mathrm{~s}, 1 \mathrm{H}, \mathrm{NH}-\mathrm{DHP}), 6.76\left(\mathrm{~d}, 2 \mathrm{H}, \mathrm{J}=8.0 \mathrm{~Hz}, \mathrm{C}_{5}-\mathrm{H}\right.$, thiazole- $\left.\mathrm{H}\right), 6.66-6.64\left(\mathrm{~m}, 2 \mathrm{H}, \mathrm{C}_{2}-\mathrm{H}, \mathrm{C}_{6}-\mathrm{H}\right.$ ), $5.05\left(\mathrm{~s}, 1 \mathrm{H}, \mathrm{DHP} \mathrm{C}_{4}-\mathrm{H}\right), 3.65\left(\mathrm{~s}, 3 \mathrm{H}, \mathrm{CH}_{3}-\mathrm{O}\right), 3.58\left(\mathrm{~s}, 3 \mathrm{H}, \mathrm{CH}_{3}-\mathrm{O}\right), 2.49-2.46(\mathrm{~m}, 2 \mathrm{H}$, cyclohexanone $\left.\mathrm{C}_{8}-\mathrm{H}\right), 2.24-2.19\left(\mathrm{~m}, 5 \mathrm{H}\right.$, cyclohexanone $\mathrm{C}_{6}-\mathrm{H}$, thiazole- $\left.\mathrm{CH}_{3}\right), 2.10\left(\mathrm{~s}, 3 \mathrm{H}, \mathrm{DHP}-\mathrm{CH}_{3}\right), 1.94-1.76(2 \times \mathrm{m}$, 2H, cyclohexanone $\left.\mathrm{C}_{7}-\mathrm{H}\right) .{ }^{13} \mathrm{C}-\mathrm{NMR}(125 \mathrm{MHz}$, DMSO-d 6 ): 194.66, 167.97, 167.53, 152.10, 148.62, 147.43, 140.14, 138.35, 119.62, 112.12, 111.96, 110.28, 78.20, 55.88, 55.61, 53.32, 53.13, 37.32, 37.07, 26.70, 26.79, 21.35, 17.71, 17.33. (IR (KBr) v ( $\left.\mathrm{cm}^{-1}\right)$ : 3229 (DHP N-H), 2937 (C-H, aromatic), 2837 (C-H, aliphatic), 1654, 1620 (C=O, amide, ketone); MS m/z (\%): 437 (25) [M - 2] ${ }^{+}, 324$ (100), 308 (3), 280 (8). Anal. Calcd: C, 63.14; N, 9.60; O, 14.63. Found: C, 63.03; N, 9.46; O, 14. 46.

4-(2,4-Dichlorophenyl)-2-methyl-N-(2-methylthiazol-4-yl)-5-oxo-5,6,7,8-tetrahydroquinoline-3-carboxamide (B1): Yield 35\%; yellow powder; mp. $248{ }^{\circ} \mathrm{C} ;{ }^{1} \mathrm{H}-\mathrm{NMR}\left(500 \mathrm{MHz}, \mathrm{DMSO}-d_{6}\right) \delta: 12.49(\mathrm{~s}, 1 \mathrm{H}$, amide $\mathrm{N}-\mathrm{H}), 7.58\left(\mathrm{~s}, 1 \mathrm{H}, \mathrm{C}_{5}-\mathrm{H}\right), 7.30\left(\mathrm{~d}, 2 \mathrm{H}, J=8.5 \mathrm{~Hz}, \mathrm{C}_{2}-\mathrm{H}, \mathrm{C}_{3}-\mathrm{H}\right), 6.76(\mathrm{~s}, 1 \mathrm{H}$, thiazole-H), $3.17(\mathrm{~m}, 2 \mathrm{H}$, cyclohexanone $\left.\mathrm{C}_{8}-\mathrm{H}\right), 2.60-2.55\left(\mathrm{~m}, 2 \mathrm{H}\right.$, cyclohexanone $\left.\mathrm{C}_{6}-\mathrm{H}\right), 2.50\left(\mathrm{~s}, 3 \mathrm{H}\right.$, thiazole- $\left.\mathrm{CH}_{3}\right), 2.24(\mathrm{~s}$, $\left.3 \mathrm{H}, \mathrm{DHP}-\mathrm{CH}_{3}\right), 2.08\left(\mathrm{~m}, 2 \mathrm{H}\right.$, cyclohexanone $\left.\mathrm{C}_{7}-\mathrm{H}\right) .{ }^{13} \mathrm{C}-\mathrm{NMR}\left(125 \mathrm{MHz}, \mathrm{DMSO}-\mathrm{d}_{6}\right)$ : 197.06, 164.86, 164.46, 158.40, 156.61, 147.39, 143.96, 135.67, 133.25, 133.09, 131.16, 128.60, 127.04, 123.70, 108.88, 57.92, 33.23, 23.31, 21.43, 19.02, 17.23. IR (KBr) $\vee\left(\mathrm{cm}^{-1}\right)$ : 3179 (DHP N-H), 3062 (C-H, aromatic), 2953 (C-H, aliphatic), 1692, 1640 (C=O, amide, ketone); MS m/z (\%): 447 (2) [M + 2] $]^{+}, 445$ (6) [M], 410 (50), 332 (92), 296 (19), 272 (28), 165 (18), 98 (17), Anal. Calcd: C, 56.51; N, 9.41; O, 7.17. Found: C, 56.35; N, 9.32; O, 7.01 . 
4-(4-Bromophenyl)-2-methyl-N-(2-methylthiazol-4-yl)-5-oxo-5,6,7,8-tetrahydroquinoline-3-carboxamide (B2): Yield 30\%; yellow powder; mp. $261{ }^{\circ} \mathrm{C} ;{ }^{1} \mathrm{H}-\mathrm{NMR}\left(500 \mathrm{MHz}, \mathrm{DMSO}-d_{6}\right) \delta: 12.42(\mathrm{~s}, 1 \mathrm{H}$, amide N-H), 7.47 $\left(\mathrm{d}, 2 \mathrm{H}, J=7.0 \mathrm{~Hz}, \mathrm{C}_{3}-\mathrm{H}, \mathrm{C}_{5}-\mathrm{H}\right), 7.08\left(\mathrm{~d}, 2 \mathrm{H}, J=7.0 \mathrm{~Hz}, \mathrm{C}_{2}-\mathrm{H}, \mathrm{C}_{6}-\mathrm{H}\right), 6.76(\mathrm{~s}, 1 \mathrm{H}$, thiazole-H), $3.14(\mathrm{t}, 2 \mathrm{H}, J$ $=6.0 \mathrm{~Hz}$, cyclohexanone $\left.\mathrm{C}_{8}-\mathrm{H}\right), 2.58\left(\mathrm{t}, 2 \mathrm{H}\right.$, cyclohexanone $\left.\mathrm{C}_{6}-\mathrm{H}\right), 2.47\left(\mathrm{~s}, 3 \mathrm{H}\right.$, thiazole- $\left.\mathrm{CH}_{3}\right), 2.23(\mathrm{~s}, 3 \mathrm{H}$, DHP-CH 3 ), 2.11-2.08 (m, 2H, cyclohexanone $\left.\mathrm{C}_{7}-\mathrm{H}\right) .{ }^{13} \mathrm{C}-\mathrm{NMR}\left(125 \mathrm{MHz}, \mathrm{DMSO}-\mathrm{d}_{6}\right):$ 197.37, 165.07, 164.94, 157.79, 156.67, 147.34, 146.86, 136.86, 131.48, 130.80, 130.34, 124.08, 121.20, 108.80, 79.63, 33.36, 23.12, 21.39, 17.24. IR (KBr) v ( $\left.\mathrm{cm}^{-1}\right)$ : 3182 (DHP N-H), 3048 (C-H, aromatic), 2947 (C-H, aliphatic), 1693, 1644 (C=O, amide, ketone); MS m/z (\%): $457(21)[\mathrm{M}+2]^{+}, 455(20)[\mathrm{M}]^{+}, 342(100), 262$ (7), 235 (25), 162 (16), Anal. Calcd: C, 55.27; N, 9.21; O, 7.01. Found: C, 55.17; N, 9.16; O, 6.84.

4-(3-Chlorophenyl)-2-methyl-N-(2-methylthiazol-4-yl)-5-oxo-5,6,7,8-tetrahydroquinoline-3-carboxamide (B3): Yield 25\%; yellow powder; mp. $241{ }^{\circ} \mathrm{C} ;{ }^{1} \mathrm{H}-\mathrm{NMR}\left(500 \mathrm{MHz}, \mathrm{DMSO}-d_{6}\right) \delta: 12.41$ (s, 1H, amide N-H), 7.31-7.27 (m, 2H, C $\left.4-\mathrm{H}, \mathrm{C}_{5}-\mathrm{H}\right), 7.20\left(\mathrm{~s}, 1 \mathrm{H}, \mathrm{C}_{2}-\mathrm{H}\right), 7.09\left(\mathrm{~d}, 1 \mathrm{H}, \mathrm{J}=7.0 \mathrm{~Hz}, \mathrm{C}_{6}-\mathrm{H}\right), 6.75(\mathrm{~s}, 1 \mathrm{H}$, thiazole-H), $3.15\left(\mathrm{t}, 2 \mathrm{H}, \mathrm{J}=6.0 \mathrm{~Hz}\right.$, cyclohexanone $\left.\mathrm{C}_{8}-\mathrm{H}\right), 2.67-2.51\left(\mathrm{~m}, 2 \mathrm{H}\right.$, cyclohexanone $\left.\mathrm{C}_{6}-\mathrm{H}\right), 2.47(\mathrm{~s}, 3 \mathrm{H}$, thiazole- $\left.\mathrm{CH}_{3}\right), 2.23\left(\mathrm{~s}, 3 \mathrm{H}, \mathrm{DHP}-\mathrm{CH}_{3}\right), 2.12-2.08\left(\mathrm{~m}, 2 \mathrm{H}\right.$, cyclohexanone $\left.\mathrm{C}_{7}-\mathrm{H}\right) .{ }^{13} \mathrm{C}-\mathrm{NMR}(125 \mathrm{MHz}$, DMSO-d $)$ : 197.26, 164.95, 157.63, 156.68, 147.31, 146.36, 139.61, 132.41, 131.50, 129.69, 128.08, 127.74, $126.80,123.92,108.76,56.49,33.37,23.11,21.35,19.01,17.22$. IR (KBr) v ( $\left.\mathrm{cm}^{-1}\right): 3154$ (DHP N-H), 3062 (C-H, aromatic), 2924 (C-H, aliphatic), 1694, 1672 (C=O, amide, ketone); MS m/z (\%): $413(32)[\mathrm{M}+2]^{+}$, 411 (13) [M], 300 (58), 298 (100), 280 (12), 165 (21), Anal. Calcd: C, 61.24; N, 10.20; O, 7.77; Found: C, 61.13; N, 10.16; O, 7.56.

2-Methyl-N-(2-methylthiazol-4-yl)-5-oxo-4-(3,4,5-trimethoxyphenyl)-5,6,7,8-tetrahydroquinoline-3-carboxamide (B4): Yield 30\%; yellow powder; mp. $238{ }^{\circ} \mathrm{C} ;{ }^{1} \mathrm{H}-\mathrm{NMR}\left(500 \mathrm{MHz}, \mathrm{DMSO}-d_{6}\right) \delta: 12.39$ (s, 1H, amide $\mathrm{N}-\mathrm{H}), 6.76\left(\mathrm{~s}, 1 \mathrm{H}\right.$, thiazole-H), $6.46\left(\mathrm{~s}, 2 \mathrm{H}, \mathrm{C}_{2}-\mathrm{H}, \mathrm{C}_{6}-\mathrm{H}\right), 3.61\left(\mathrm{~s}, 6 \mathrm{H},-\mathrm{OCH}_{3}\right), 3.58\left(\mathrm{~s}, 3 \mathrm{H},-\mathrm{OCH}_{3}\right)$, $3.15\left(\mathrm{t}, 2 \mathrm{H}, \mathrm{J}=6.0 \mathrm{~Hz}\right.$, cyclohexanone $\left.\mathrm{C}_{8}-\mathrm{H}\right), 2.67\left(\mathrm{t}, 2 \mathrm{H}, \mathrm{J}=6.0 \mathrm{~Hz}\right.$, cyclohexanone $\left.\mathrm{C}_{6}-\mathrm{H}\right), 2.47(\mathrm{~s}, 3 \mathrm{H}$, thiazole- $\left.\mathrm{CH}_{3}\right), 2.23\left(\mathrm{~s}, 3 \mathrm{H}, \mathrm{DHP}-\mathrm{CH}_{3}\right), 2.13-2.10\left(\mathrm{~m}, 2 \mathrm{H}\right.$, cyclohexanone $\left.\mathrm{C}_{7}-\mathrm{H}\right) .{ }^{13} \mathrm{C}-\mathrm{NMR}(125 \mathrm{MHz}$, DMSO-d $)_{6}$ : $197.29,165.47,164.69,157.22,156.88,152.46,147.94,147.28,137.13,132.97,131.83,124.52$, 108.60,106.26, 102.78,79.63, 60.38, 56.18, 33.36, 23.06, 21.47, 17.26. IR (KBr) v (cm $\left.{ }^{-1}\right): 2994(\mathrm{C}-\mathrm{H}$, aromatic), 2960 (C-H, aliphatic), 1693, 1664 (C=O, amide, ketone); MS m/z (\%): 467 (40) [M] ${ }^{+}, 354$ (100), 338 (16), 323 (21), 311 (68), Anal. Calcd: C, 61.66; N, 8.99; O, 17.11. Found: C, 61.46; N, 8.75; O, 17.07.

4-(4-Chlorophenyl)-2-methyl-N-(2-methylthiazol-4-yl)-5-oxo-5,6,7,8-tetrahydroquinoline-3-carboxamide (B5): Yield 27\%; yellow powder; mp. $251{ }^{\circ} \mathrm{C} ;{ }^{1} \mathrm{H}-\mathrm{NMR}\left(500 \mathrm{MHz}, \mathrm{DMSO}-\mathrm{d}_{6}\right) \delta: 12.41$ (s, 1H, amide N-H), $7.33\left(\mathrm{~d}, 2 \mathrm{H}, \mathrm{J}=2.0 \mathrm{~Hz}, \mathrm{C}_{3}-\mathrm{H}, \mathrm{C}_{5}-\mathrm{H}\right), 7.15\left(\mathrm{~d}, 2 \mathrm{H}, \mathrm{J}=2.0 \mathrm{~Hz}, \mathrm{C}_{2}-\mathrm{H}, \mathrm{C}_{6}-\mathrm{H}_{1}, 6.75\right.$ (s, 1H, thiazole-H), 3.14 $\left(\mathrm{m}, 2 \mathrm{H}\right.$, cyclohexanone $\left.\mathrm{C}_{8}-\mathrm{H}\right), 2.50\left(\mathrm{~s}, 3 \mathrm{H}\right.$, thiazole- $\mathrm{CH}_{3}$ overlapped with DMSO peak), 2.57 (m, $2 \mathrm{H}$, cyclohexanone $\left.\mathrm{C}_{6}-\mathrm{H}\right), 2.22\left(\mathrm{~s}, 3 \mathrm{H}, \mathrm{DHP}-\mathrm{CH}_{3}\right), 2.09\left(\mathrm{~s}, \mathrm{~m}, 2 \mathrm{H}\right.$, cyclohexanone $\left.\mathrm{C}_{7}-\mathrm{H}\right) .{ }^{13} \mathrm{C}-\mathrm{NMR}(125 \mathrm{MHz}$, DMSO-d 6 ): 197.36, 165.10, 164.93, 157.58, 156.68, 147.33, 146.86, 136.46, 132.53, 131.59, 130.05, 127.89, 124.11, 108.77, 30.36, 23.11, 21.39, 21.27, 17.21. (IR (KBr) $v\left(\mathrm{~cm}^{-1}\right)$ : 3079 (C-H, aromatic), 2967 (C-H, aliphatic), 1692, 1681 (C=O, amide, ketone); MS m/z (\%): $413(10)[\mathrm{M}+2]^{+}, 411(28)[\mathrm{M}+1]^{+}, 300(61)$, 280 (13), 268(6), 165(21), Anal. Calcd: C, 61.24; N, 10.20; O, 7.77. Found: C, 61.12; N, 10.11; O, 7.24.

4-(3-Ethoxy-4-hydroxyphenyl)-2-methyl-N-(2-methylthiazol-4-yl)-5-oxo-5,6,7,8-tetrahydroquinoline-3-carboxamide (B6): Yield 29\%; yellow powder; mp. $267{ }^{\circ} \mathrm{C} ;{ }^{1} \mathrm{H}-\mathrm{NMR}\left(500 \mathrm{MHz}, \mathrm{DMSO}-\mathrm{d}_{6}\right) \delta: 11.62(\mathrm{~s}, 1 \mathrm{H}$, amide $\mathrm{N}-\mathrm{H}), 8.55(\mathrm{~s}, 1 \mathrm{H}, \mathrm{OH}), 6.72\left(\mathrm{~s}, 1 \mathrm{H}, \mathrm{C}_{2}-\mathrm{H}\right), 6.66\left(\mathrm{~s}, 1 \mathrm{H}\right.$, thiazole-H), $6.59\left(\mathrm{~d}, 1 \mathrm{H}, \mathrm{J}=8.0 \mathrm{~Hz}, \mathrm{C}_{5}-\mathrm{H}\right), 6.52(\mathrm{~d}$, $\left.1 \mathrm{H}, \mathrm{J}=8.0 \mathrm{~Hz}, \mathrm{C}_{6}-\mathrm{H}\right), 3.90-3.78\left(\mathrm{~m}, 2 \mathrm{H}, \mathrm{CH}_{3}-\mathrm{CH}_{2}-\mathrm{O}\right), 2.48-2.45\left(\mathrm{~m}, 2 \mathrm{H}\right.$, cyclohexanone $\left.\mathrm{C}_{8}-\mathrm{H}\right), 2.23(\mathrm{~s}$, $3 \mathrm{H}, \mathrm{C}_{6}-\mathrm{H}$, thiazole- $\left.\mathrm{CH}_{3}\right), 2.21-2.19\left(\mathrm{~m}, 2 \mathrm{H}\right.$, cyclohexanone), $2.09\left(\mathrm{~s}, 3 \mathrm{H}, \mathrm{DHP}-\mathrm{CH}_{3}\right), 1.93-1.78(2 \times \mathrm{m}$, $2 \mathrm{H}$, cyclohexanone $\left.\mathrm{C}_{7}-\mathrm{H}\right), 1,23\left(\mathrm{t}, 3 \mathrm{H}, \mathrm{J}=7.0, \mathrm{CH}_{3}-\mathrm{CH}_{2}-\mathrm{O}\right) .{ }^{13} \mathrm{C}-\mathrm{NMR}\left(125 \mathrm{MHz}, \mathrm{DMSO}-d_{6}\right): 194.54$, 152.26, 151.76, 146.45, 146.29, 140.34, 138.59, 138.10, 134.89, 118.42, 115.54, 112.32, 110.69, 108.44, 107.74, $56.02,37.32,36.79,30.83,26.78,21.28,17.72,17.34$. IR (KBr) v (cm $\left.{ }^{-1}\right): 3320(\mathrm{O}-\mathrm{H}), 3277(\mathrm{C}-\mathrm{H}$, aromatic), 2925 (C-H, aliphatic), 1667, 1602 (C=O, amide, ketone); MS m/z (\%): 439 (5) [M + 2] $]^{+}, 326$ (8), 299 (49), 268 (23), 188 (74), 162 (100), Anal. Calcd: C, 63.00; N, 9.58; O, 14.59. Found: C, 62.87; N, 9.36; O, 14.48. 
4-(4-Methoxyphenyl)-2-methyl-N-(2-methylthiazol-4-yl)-5-oxo-5,6,7,8-tetrahydroquinoline-3-carboxamide (B7): Yield 25\%; yellow powder; mp. $166{ }^{\circ} \mathrm{C} ;{ }^{1} \mathrm{H}-\mathrm{NMR}\left(500 \mathrm{MHz}, \mathrm{DMSO}-d_{6}\right) \delta: 12.35$ (s, $1 \mathrm{H}$, amide N-H), $7.05\left(\mathrm{~d}, 2 \mathrm{H}, \mathrm{J}=8.0 \mathrm{~Hz}, \mathrm{C}_{5}-\mathrm{H}, \mathrm{C}_{3}-\mathrm{H}\right), 6.81\left(\mathrm{~d}, 2 \mathrm{H}, \mathrm{J}=8.0 \mathrm{~Hz}, \mathrm{C}_{2}-\mathrm{H}, \mathrm{C}_{6}-\mathrm{H}\right), 6.74(\mathrm{~s}, 1 \mathrm{H}$, thiazole-H), $3.71(\mathrm{~s}$, $\left.3 \mathrm{H}, \mathrm{CH}_{3}-\mathrm{O}\right), 3.37\left(\mathrm{~s}, 3 \mathrm{H}\right.$, thiazole- $\left.\mathrm{CH}_{3}\right), 3.12\left(\mathrm{t}, 2 \mathrm{H}\right.$, cyclohexanone $\left.\mathrm{C}_{8}-\mathrm{H}\right), 2.57(\mathrm{t}, 2 \mathrm{H}$, cyclohexanone $\left.\mathrm{C}_{6}-\mathrm{H}\right), 2.22\left(\mathrm{~s}, 3 \mathrm{H}, \mathrm{DHP}-\mathrm{CH}_{3}\right), 2.09-2.07$ (m, 2H, cyclohexanone $\left.\mathrm{C}_{7}-\mathrm{H}\right) .{ }^{13} \mathrm{C}-\mathrm{NMR}\left(125 \mathrm{MHz}, \mathrm{DMSO}-d_{6}\right)$ : 197.44, 165.52, 164.61, 158.92, 157.27, 156.85, 148.01, 147.27, 131.96, 129.62, 124.74, 113.33, 108.64, 79.63, 55.37, 33.40, 23.07, 21.48, 19.02, 17.24. (IR (KBr) v ( $\left.\mathrm{cm}^{-1}\right)$ : 3011 (C-H, aromatic), 2924 (C-H, aliphatic), 1691, 1609 (C=O, amide, ketone); MS m/z (\%): 407 (4) [M] $]^{+}, 294$ (21), 408 (26), 269 (62), 252 (19), 162 (100), Anal. Calcd: C, 64.85; N, 10.31; O, 11.78. Found: C, 64.65; N, 10.41; O, 11.64 .

4-(3,4-Dimethoxyphenyl)-2-methyl-N-(5-methylthiazol-2-yl)-5-oxo-5,6,7,8-tetrahydroquinoline-3-carboxamide (B8): Yield 30\%; yellow powder; mp. $219{ }^{\circ} \mathrm{C} ;{ }^{1} \mathrm{H}-\mathrm{NMR}\left(500 \mathrm{MHz}, \mathrm{DMSO}-d_{6}\right) \delta: 12.42(\mathrm{~s}, 1 \mathrm{H}$, amide $\mathrm{N}-\mathrm{H}), 6.83\left(\mathrm{~d}, 1 \mathrm{H}, J=8.0 \mathrm{~Hz}, \mathrm{C}_{6}-\mathrm{H}\right), 6.79\left(\mathrm{~s}, 1 \mathrm{H}, J=8.0 \mathrm{~Hz}, \mathrm{C}_{2}-\mathrm{H}\right), 6.76(\mathrm{~s}, 1 \mathrm{H}$, thiazole-H), $6.64(\mathrm{~d}, 1 \mathrm{H}, J$ $\left.=8.0 \mathrm{~Hz}, \mathrm{C}_{5}-\mathrm{H}\right), 3.71\left(\mathrm{~s}, 3 \mathrm{H}, \mathrm{CH}_{3}-\mathrm{O}\right), 3.60\left(\mathrm{~s}, 3 \mathrm{H}, \mathrm{CH}_{3}-\mathrm{O}\right), 3.12\left(\mathrm{t}, 2 \mathrm{H}\right.$, cyclohexanone $\left.\mathrm{C}_{8}-\mathrm{H}\right), 2.59-2.55$ $\left(\mathrm{m}, 2 \mathrm{H}\right.$, cyclohexanone $\left.\mathrm{C}_{6}-\mathrm{H}\right), 2.45\left(\mathrm{~s}, 3 \mathrm{H}\right.$, thiazole- $\left.\mathrm{CH}_{3}\right), 2.23\left(\mathrm{~s}, 3 \mathrm{H}, \mathrm{DHP}-\mathrm{CH}_{3}\right), 2.09-2.11-2.08(\mathrm{~m}, 2 \mathrm{H}$, cyclohexanone $\left.\mathrm{C}_{7}-\mathrm{H}\right) .{ }^{13} \mathrm{C}-\mathrm{NMR}\left(125 \mathrm{MHz}, \mathrm{DMSO}-\mathrm{d}_{6}\right): 197.45,165.58,164.66,157.18,156.88,148.50$, $148.05,147.93,147.32,147.25,131.94,129.73,124.84,121.10,112.47,111.34,108.65,63.26,55.76,33.37$, 23.05, 21.49, 17.25. (IR (KBr) v ( $\left.\mathrm{cm}^{-1}\right): 3117$ (C-H, aromatic), 2936 (C-H, aliphatic), 1667, 1604 (C=O, amide, ketone); MS m/z (\%): 437 (1) [M + 2] ${ }^{+}, 407$ (4), 294 (18), 269 (65), 252 (15), 162 (100), Anal. Calcd: C, 63.14; N, 9.60; O, 14.63. Found: C, 62.59; N, 9.40; O, 14.82 .

\subsection{Biological Evaluation}

\subsubsection{Cell Lines}

Cell lines used for cytotoxicity assays included MCF-7 (human breast adenocarcinoma), A549 (human lung adenocarcinoma), K562 (human chronic myelogenous leukemia) and HEK-293 (human embryonic kidney) cells and were obtained from the Iranian Biological Resource Center, Tehran, Iran. MES-SA-DX5 multidrug resistant human uterine sarcoma, over-expressing P-gp and their parental non-resistant MES-SA cell lines were purchased from Sigma-Aldrich (St. Louis, MO, USA). All cells, except for HEK-293, were cultured in RPMI 1640 supplemented with 10\% FBS and 100 units $/ \mathrm{mL}$ penicillin-streptomycin at $37{ }^{\circ} \mathrm{C}$ in humidified air containing $5 \% \mathrm{CO}_{2}$. HEK-293 cells were maintained in DMEM-F12 medium containing L-glutamine $2 \mathrm{mM}$ supplemented with FBS and penicillin-streptomycin. MES-SA-DX5 cells were maintained in media containing $100 \mathrm{nM}$ doxorubicin in order to ensure that only drug-resistant cells continue to grow.

\subsubsection{Reagents}

RPMI 1640 and DMEM-F12 growth mediua, L-glutamine, penicillin and streptomycin were purchased from Biosera (Nuaille, France). Fetal bovine serum (FBS) was obtained from Gibco (Carlsbad, CA, USA). Doxorubicin, cisplatin and 3-(4,5-dimethylthiazol-2-yl)-2,5-diphenyltetrazolium bromide (MTT) were purchased from EBEWE Pharma (Unterach, Austria) and Sigma Aldrich (St. Louis, MO, USA).

\subsubsection{MDR Reversal Assay}

Rhodamine 123 (Rh123) is a well-known substrate of P-gp and it is readily pumped out of the cells by this ABC transporter. The amount of retained Rh123 in the cells indicates the efflux function of the target transporter. Flow cytometric analysis was used for assessment of intracellular Rh123 as previously described [23].

Briefly, a suspension of the multidrug resistant uterine sarcoma MES-SA-DX5 cells at a density of $5 \times 10^{5}$ cells $/ \mathrm{mL}$ in growth medium was prepared. Four-hundred microliters $(400 \mu \mathrm{L})$ of the synthesized compounds with final concentration of 5,10 , and $25 \mu \mathrm{M}$ were added to $500 \mu \mathrm{L}$ of the cell suspension. Verapamil was also tested as a positive control. After an incubation of $20 \mathrm{~min}$, 
$50 \mu \mathrm{L}$ of Rh123 at a final concentration of $5 \mu \mathrm{M}$ was added and incubated for further $30 \mathrm{~min}$ at $37^{\circ} \mathrm{C}$. The cells were then centrifuged and washed twice with ice-cold PBS, and then resuspended in PBS and kept on ice. Rh123 accumulated in cells was then quantified by a FACSCalibur flow cytometer (Becton Dickinson, San Jose, CA, USA) with excitation and emission wavelengths of 488 and 530 $\mathrm{nm}$, respectively. Geometric means of fluorescence intensity values were determined using Flowing Software (http://flowingsoftware.btk.fi/).

\subsubsection{Cell Cycle Analysis}

The analysis of cells in different phases of cell cycle and sub-G1 was performed using propidium iodide (PI)-RNase assay by flow cytometry. MES-SA-DX5 cells were seeded in 12 -well plates $\left(1 \times 10^{6}\right.$ cells/well) and treated with different concentrations of synthesized compounds for $24 \mathrm{~h}$. The cells were then collected, washed with PBS, and fixed with $70 \%$ ethanol overnight at $-20^{\circ} \mathrm{C}$. After at least $24 \mathrm{~h}$, fixed cells were washed with PBS and subsequently stained with a DNA staining solution containing PI $20 \mu \mathrm{g} / \mathrm{mL}$ and RNase $200 \mu \mathrm{g} / \mathrm{mL}$ at room temperature for $30 \mathrm{~min}$ in the dark. Twenty thousand cells of each sample were analyzed using a BD FACSCalibur flow cytometer (BD Biosciences, USA) and the amount of the cells in sub-G1, G0/G1, S, and G2/M phases were estimated using CellQuest (Becton Dickinson, San Jose, CA, USA) software.

\subsubsection{Cell Viability Assay}

Cytotoxicity of the test compounds were evaluated by MTT assay [24]. In this method, reduction of MTT, a yellow tetrazolium salt to the purple formazan, by cellular dehydrogenase enzymes is determined as an index of cell viability. Cancer cells were seeded into 96-well plates $\left(3-5 \times 10^{3}\right.$ cells/well) and incubated for $24 \mathrm{~h}$ at $37^{\circ} \mathrm{C}$. Afterwards, four different concentrations of synthesized derivatives were added in triplicate and the cells were incubated at $37^{\circ} \mathrm{C}$ for another $72 \mathrm{~h}$, after which the media was replaced with MTT solution at a concentration of $0.5 \mathrm{mg} / \mathrm{mL}$ was added for MTT assay. After another $4 \mathrm{~h}$, formazan crystals were dissolved in $200 \mu \mathrm{L}$ DMSO for $90 \mathrm{~min}$ and absorbance was measured at a wavelength of $570 \mathrm{~nm}$ with background correction at $650 \mathrm{~nm}$ using a microplate reader (model 680, Bio-Rad, Hercules, CA, USA) and $\mathrm{IC}_{50}$ for each compound was calculated with CurveExpert version 1.34 for Windows.

\subsection{Statistical Analysis}

All experiments were carried out in triplicate and were repeated 3-5 times. The results are reported as mean \pm S.E.M.. The differences between various treatments were analyzed by one-way ANOVA with an LSD post hoc test. Statistical analysis was performed using the SPSS program version 14.0 (Chicago, IL, USA) for Windows.

\section{Results and Discussion}

\subsection{Synthesis}

The synthetic routes for the target compounds A1-A8 and B1-B8 are depicted in Scheme 1 and the structures are presented in Table 1. Compound 1-((2-methylthiazol-4-yl) amino) pentane-2,4-dione was synthesized by the reaction of the commercially available 2-methylthiazol-4-amine with 2,2,6-trimethyl-4H-1,3-dioxin-4-one in xylene under reflux condition. According to Scheme 1, the final products were synthesized by treatment of obtained intermediate with 1,3-cyclohexadione and different appropriate arylaldehydes in the presence of excess amounts of ammonium acetate in refluxing ethanol. In order to synthesis the tetrahydroquinoline derivatives; the corresponding hexahydroquinoline compound was oxidized in the presence of $\mathrm{MnO}_{2}$ in ethanol under reflux condition for 24-48 h. 


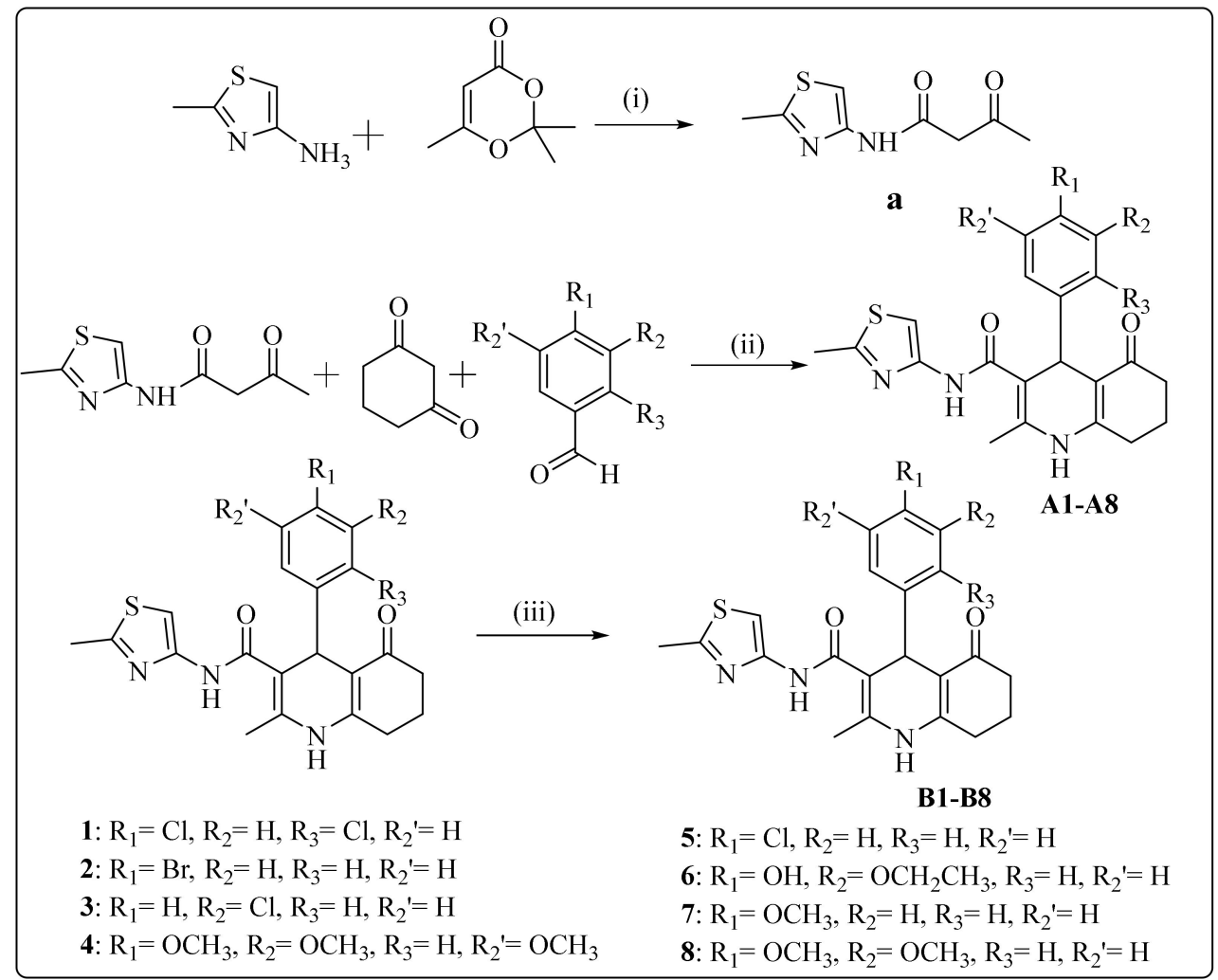

Scheme 1. Synthesis of the 5-oxo-hexahydroquinoline derivatives and their tetrahydroquinoline counterparts. Reagents and conditions: (i) xylene, reflux, 2-4 h; (ii) $\mathrm{CH}_{3} \mathrm{COONH}_{4}$, ethanol, reflux, 24 h; (iii) $\mathrm{MnO}_{2}$, ethanol, reflux, 24-48 h.

Table 1. Chemical structures of synthesized 5-oxo-hexahyroquinoline derivatives and their tetrahydroquinoline counterparts.

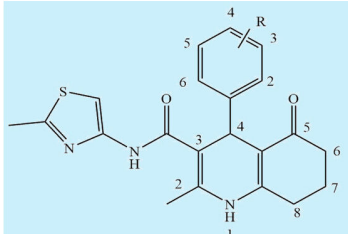

A1-A8

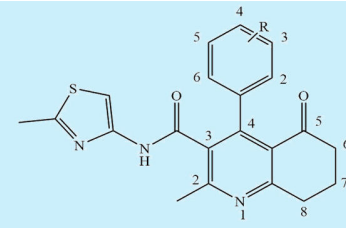

B1-B8

\begin{tabular}{|c|c|c|c|c|c|}
\hline Compound & Ar & MW & Compound & Ar & MW \\
\hline A1 & & 448.36 & B1 & & 446.35 \\
\hline A2 & & 458.37 & B2 & & 456.36 \\
\hline A3 & & 413.92 & B3 & & 411.90 \\
\hline A4 & & 469.56 & B4 & & 467.54 \\
\hline A5 & & 413.92 & B5 & & 411.90 \\
\hline
\end{tabular}


Table 1. Cont.

Compound

\subsection{Biological Evaluations}

\subsubsection{MDR Reversal Assay}

Accumulation of Rhodamine123 (Rh123), caused by inhibition of P-gp-mediated efflux, was determined by flow cytometry in the multidrug resistant uterine sarcoma MES-SA-DX5 cell line. Verapamil was used as a positive control. MES-SA-DX5 is a resistant cell line, which overexpresses P-gp as a result of constant exposure to doxorubicin. Alterations in the amount of the fluorescent Rh123 retained inside the MES-SA-DX5 cells can be plausibly related to the inhibition of the activity of P-gp efflux pump in the cells (Figure 1). The ratio of the geometric mean value of cells treated with synthesized compounds to the geometric mean value of the control untreated cells are show in Figure 2. The findings demonstrate a clear dose-dependent effect at 5, 10, and $25 \mu \mathrm{M}$ on Rh123 accumulation for most of the compounds. Compounds A1, A2, and $\mathbf{B} 2$ showed the highest P-gp inhibitory activities.

\subsubsection{Effect of Synthesized Derivatives on Cell Cycle}

The effect of the most potent compounds on the cell cycle distribution and apoptosis induction in MES-SA-DX5 resistant cells was evaluated using propidium iodide (PI)-RNase assay by flow cytometry. Table 2 shows the distribution of the cells in the sub-G1, G0/G1, S and G2/M phases of the cell cycle. The results indicate that the number of cells in sub-G1 phase, which shows the apoptotic cells, is significantly increased after treatment with $100 \mu \mathrm{M}$ concentrations of A1, A2, A3, A5, B1, B2, and B5 compounds. Therefore, it could be concluded that these compounds cause cytotoxicity in drug resistant MES-SA-DX5 cells by induction of apoptosis in these cells. Furthermore, treatment of MES-SA-DX5 cells with compounds A1 and B1 caused a considerable increase in G2/M and a decrease in G0/G1 phase cells. Representative histograms of the most potent derivatives are shown in Figure 3.
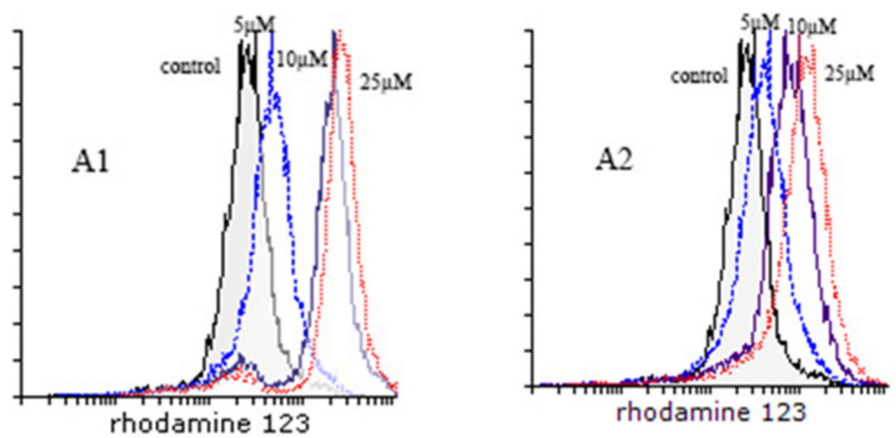

Figure 1. Cont. 

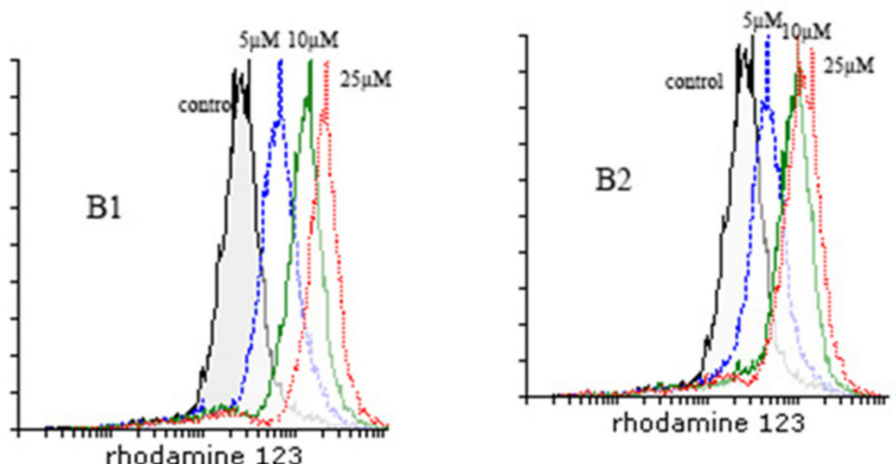

Figure 1. Flow cytometric detection of Rhodamine123 efflux in MES-SA-DX5 drug resistant cells. Cells were suspended in RPMI 1640 and treated with synthesized derivatives A1, A2, B1, and B2. After incubation for $20 \mathrm{~min}, 5 \mu \mathrm{M}$ Rh123 was added and the cells incubated for another $20 \mathrm{~min}$ at $37{ }^{\circ} \mathrm{C}$. Afterwards, the cells were centrifuged and washed twice with ice-cold PBS and resuspended in PBS. The fluorescence signal caused by the presence of Rh123 inside the cells was measured using a flow cytometer with excitation and emission wavelengths of $488 \mathrm{~nm}$ and $530 \mathrm{~nm}$, respectively. Representative histograms of cells treated with different concentrations of test compounds are shown.

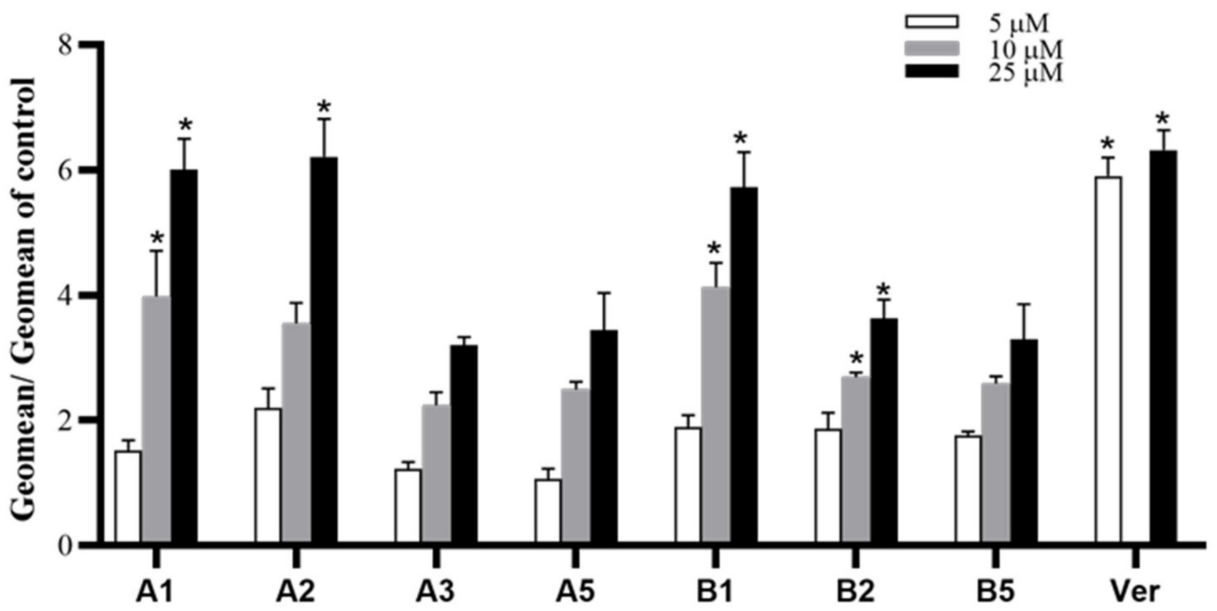

Figure 2. MDR reversal assessed by flow cytometric detection of Rhodamine123 efflux in MES-SA-DX5 cells. Cells were suspended in RPMI 1640 and treated with verapamil (Ver, positive control) or synthesized derivatives. After incubation for $20 \mathrm{~min}, 5 \mu \mathrm{M}$ Rh123 was added, the cells were incubated for another $20 \mathrm{~min}$ at $37^{\circ} \mathrm{C}$ and then centrifuged and washed twice with ice-cold PBS and resuspended in PBS. The fluorescence caused by the presence of Rh123 in cells was measured using a flow cytometer with excitation and emission wavelengths of $488 \mathrm{~nm}$ and $530 \mathrm{~nm}$, respectively. The values represent the mean \pm S.E.M. of 3-5 experiments. * The difference between treated and controlled cells are statistically significant $(p<0.05)$.

Table 2. Flow cytometric analysis of cell cycle distribution of MES-SA-DX5 cells treated with synthesized compounds.

\begin{tabular}{ccccc}
\hline Compound & Sub G1 & G0/G1 & S & G2/M \\
\hline Control & $1.99 \pm 1.2$ & $52.71 \pm 0.8$ & $20.29 \pm 0.7$ & $24.99 \pm 0.6$ \\
A1 $(10 \mu \mathrm{M})$ & $0.61 \pm 0.2$ & $52.32 \pm 1.8$ & $21.85 \pm 1.0$ & $25.12 \pm 1.7$ \\
A1 $(25 \mu \mathrm{M})$ & $0.71 \pm 0.2$ & $53.30 \pm 0.9$ & $20.96 \pm 1.2$ & $25.01 \pm 0.7$ \\
A1 $(100 \mu \mathrm{M})$ & $4.23 \pm \mathbf{0 . 6}$ & $39.18 \pm 1.7$ & $21.12 \pm 1.6$ & $35.48 \pm 2.7$ \\
A2 $(10 \mu \mathrm{M})$ & $1.21 \pm 0.7$ & $56.45 \pm 1.1$ & $18.90 \pm 0.2$ & $23.45 \pm 0.2$ \\
A2 $(25 \mu \mathrm{M})$ & $1.71 \pm 1.1$ & $59.47 \pm 3.0$ & $18.53 \pm 1.7$ & $20.23 \pm 0.7$ \\
A2 $(100 \mu \mathrm{M})$ & $\mathbf{6 . 8 8} \pm \mathbf{3 . 0 ^ { * }}$ & $50.57 \pm 2.8$ & $19.27 \pm 0.3$ & $18.37 \pm 2.6$ \\
A3 $(10 \mu \mathrm{M})$ & $0.51 \pm 0.1$ & $50.35 \pm 4.5$ & $18.23 \pm 2.6$ & $23.25 \pm 1.6$ \\
\hline
\end{tabular}


Table 2. Cont.

\begin{tabular}{ccccc}
\hline Compound & Sub G1 & G0/G1 & S & G2/M \\
\hline A3 $(25 \mu \mathrm{M})$ & $0.97 \pm 0.2$ & $56.18 \pm 1.2$ & $19.70 \pm 2.0$ & $23.08 \pm 1.0$ \\
A3 $(100 \mu \mathrm{M})$ & $\mathbf{3 . 5 9} \pm \mathbf{0 . 7}$ & $53.64 \pm 1.4$ & $13.31 \pm 1.0$ & $29.46 \pm 1.8$ \\
A5 $(10 \mu \mathrm{M})$ & $0.65 \pm 0.2$ & $56.07 \pm 0.3$ & $19.03 \pm 0.9$ & $24.20 \pm 1.2$ \\
A5 $(25 \mu \mathrm{M})$ & $0.70 \pm 0.3$ & $58.03 \pm 0.7$ & $18.90 \pm 0.9$ & $22.33 \pm 0.5$ \\
A5 $(100 \mu \mathrm{M})$ & $\mathbf{3 . 1 7} \pm \mathbf{0 . 6}$ & $48.92 \pm 1.4$ & $18.58 \pm 0.6$ & $29.32 \pm 1.2$ \\
B1 $(10 \mu \mathrm{M})$ & $0.64 \pm 0.1$ & $49.10 \pm 3.7$ & $21.27 \pm 2.1$ & $29.03 \pm 2.1$ \\
B1 $(25 \mu \mathrm{M})$ & $0.91 \pm 0.0$ & $51.13 \pm 2.4$ & $20.90 \pm 2.0$ & $27.03 \pm 0.6$ \\
B1 $(100 \mu \mathrm{M})$ & $\mathbf{5 . 0 8} \pm \mathbf{0 . 7}$ & $24.00 \pm 4.1$ & $25.17 \pm 0.7$ & $45.77 \pm 3.4$ \\
B2 $(10 \mu \mathrm{M})$ & $0.96 \pm 0.1$ & $53.00 \pm 3.6$ & $21.80 \pm 1.5$ & $24.13 \pm 2.4$ \\
B2 $(25 \mu \mathrm{M})$ & $1.57 \pm 0.4$ & $55.83 \pm 2.6$ & $20.30 \pm 1.7$ & $22.23 \pm 1.4$ \\
B2 $(100 \mu \mathrm{M})$ & $\mathbf{4 . 2 5} \pm \mathbf{0 . 5}$ & $47.00 \pm 0.6$ & $19.48 \pm 1.8$ & $29.27 \pm 1.8$ \\
B5 $(10 \mu \mathrm{M})$ & $0.62 \pm 0.1$ & $53.87 \pm 0.7$ & $18.13 \pm 1.9$ & $27.27 \pm 2.6$ \\
B5 $(25 \mu \mathrm{M})$ & $0.69 \pm 0.1$ & $55.43 \pm 1.3$ & $17.73 \pm 1.3$ & $26.07 \pm 2.7$ \\
B5 $(100 \mu \mathrm{M})$ & $\mathbf{1 . 9 1} \pm \mathbf{0 . 3}$ & $57.58 \pm 0.9$ & $13.62 \pm 0.8$ & $26.87 \pm 0.9$ \\
Doxorubicin & $1.08 \pm 0.2$ & $34.23 \pm 3.3$ & $12.57 \pm 1.4$ & $52.10 \pm 4.4$ \\
$(2.5 \mu \mathrm{M})$ & & & & \\
Doxorubicin & $1.81 \pm 0.3$ & $21.50 \pm 2.5$ & $12.57 \pm 1.7$ & $64.13 \pm 4.2$ \\
$(5 \mu \mathrm{M})$ & & & &
\end{tabular}

Values represent mean \pm S.E.M. of 3-5 independent experiments. ${ }^{*}$ The difference with control untreated cells was significantly different $(p<0.05)$. Significantly increased sub-G1 values are shown in boldface for emphasis.

\subsubsection{Cell Viability Assay}

Cell viability of different cancer cell lines exposed to synthesized derivatives was evaluated using the MTT reduction assay. The average $\mathrm{IC}_{50}$ values in tested cell lines are summarized in Table 3. In general, the compounds had the lowest $\mathrm{IC}_{50}$ values against $\mathrm{K} 562$ cells, which is usually expected in hematological malignancies compared to solid tumors.

Table 3. Cytotoxic activity of synthetic compounds assessed by the MTT reduction assay.

\begin{tabular}{ccccccc}
\hline \multirow{2}{*}{ Compound } & \multicolumn{5}{c}{ IC $_{\mathbf{5 0}}(\boldsymbol{\mu M})$ in Cultured Cells } \\
\cline { 2 - 6 } & MCF-7 & A-549 & K562 & MES-SA-DX5 & MES-SA & HEK-293 \\
\hline A1 & $72.5 \pm 11.9$ & $48.8 \pm 1.3$ & $15.0 \pm 0.5$ & $40.1 \pm 4.7$ & $64.1 \pm 19.4$ & $28.6 \pm 4.3$ \\
A2 & $56.7 \pm 3.6$ & $87.1 \pm 6.7$ & $31.0 \pm 2.7$ & $31.5 \pm 1.5$ & $>100$ & $63.1 \pm 7.4$ \\
A3 & $>100$ & $>100$ & $56.4 \pm 7.0$ & $78.0 \pm 4.0$ & $>100$ & $93.7 \pm 11.9$ \\
A4 & $>100$ & $>100$ & $>100$ & $>100$ & - & - \\
A5 & $72.9 \pm 12.3$ & $87.4 \pm 1.5$ & $31.5 \pm 3.3$ & $40.3 \pm 3.0$ & $69.5 \pm 12.5$ & $71.1 \pm 10.1$ \\
A6 & $>100$ & $>100$ & $>100$ & $>100$ & - & - \\
A7 & $>100$ & $>100$ & $>100$ & $>100$ & - & - \\
A8 & $>100$ & $>100$ & $>100$ & $>100$ & - & - \\
B1 & $47.1 \pm 2.1$ & $60.0 \pm 3.0$ & $6.7 \pm 0.6$ & $39.8 \pm 1.6$ & $55.6 \pm 2.4$ & $39.9 \pm 5.4$ \\
B2 & $77.7 \pm 8.7$ & $86.8 \pm 5.0$ & $10.1 \pm 1.5$ & $43.6 \pm 2.8$ & $>100$ & $83.2 \pm 10.6$ \\
B3 & $>100$ & $>100$ & $50.2 \pm 2.6$ & $85.2 \pm 7.4$ & $>100$ & $>100$ \\
B4 & $>100$ & $>100$ & $>100$ & $>100$ & - & - \\
B5 & $89.5 \pm 3.5$ & $91.0 \pm 4.6$ & $10.4 \pm 1.5$ & $62.3 \pm 5.5$ & $>100$ & $64.2 \pm 1.1$ \\
B6 & $>100$ & $>100$ & $>100$ & $>100$ & - & - \\
B7 & $>100$ & $>100$ & $32.9 \pm 5.1$ & $>100$ & - & - \\
B8 & $>100$ & $>100$ & $67.5 \pm 8.0$ & $>100$ & - & - \\
Doxorubicin & $0.115 \pm 0.042$ & $0.575 \pm 0.127$ & $0.042 \pm 0.006$ & $2.2 \pm 0.3$ & $0.010 \pm 0.002$ & $0.009 \pm 0.002$ \\
Cisplatin & $26.3 \pm 7.9$ & $14.0 \pm 0.5$ & $3.3 \pm 2.3$ & $8.6 \pm 0.5$ & $1.2 \pm 0.1$ & $1.1 \pm 0.5$ \\
\hline
\end{tabular}

$\mathrm{IC}_{50}$ values are presented as mean \pm S.E.M. of 3-5 independent experiments. 

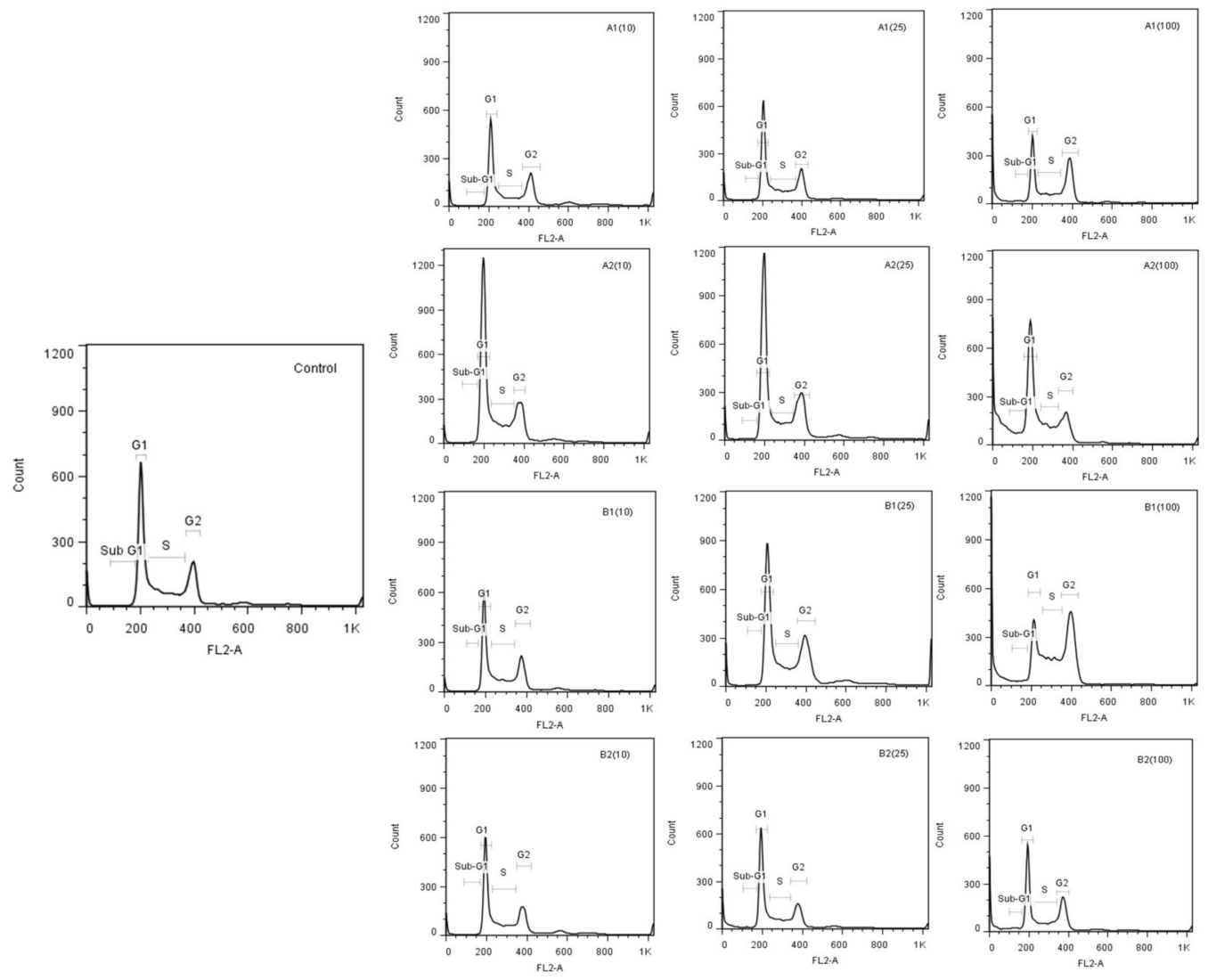

Figure 3. Effect of synthesized derivatives on cell cycle alterations in MES-SA-DX5 drug resistant cells. The cells in different phases of cell cycle were monitored using propidium iodide (PI)-RNase assay by flow cytometry. MES-SA-DX5 cells were seeded in 12-well plates $\left(1 \times 10^{6}\right.$ cells/well $)$ and treated with different concentrations of synthesized compounds for $24 \mathrm{~h}$. The cells were then collected, washed with PBS and fixed with $70 \%$ ethanol overnight at $-20{ }^{\circ} \mathrm{C}$. After at least $24 \mathrm{~h}$, fixed cells were washed with PBS and subsequently stained with a DNA staining solution containing PI $20 \mu \mathrm{g} / \mathrm{mL}$ and RNase $200 \mu \mathrm{g} / \mathrm{mL}$ at room temperature for $30 \mathrm{~min}$ in the dark. Twenty thousand cells of each sample were analyzed using a FACS Calibur flow cytometer (BD Biosciences, USA). Representative histograms of cells treated with synthesized compounds are shown. An increase in sub-G1 phase cells could be observed after treatment with A1, A2, B1, and B2 compounds.

Interestingly, among tested solid tumors, the synthesized derivatives A1, A2, A5, B1, and B2 were more effective against MES-SA-DX5 cells. These findings are particularly interesting if we note that MES-SA-DX5 is a multidrug resistant cell line and any compound effective against these cancer cells could have high potential as therapeutic agents against drug resistant tumors. We also tested the more promising derivatives against parental non-resistant MES-SA cells and the $\mathrm{IC}_{50}$ values were invariably higher in these cells compared to MES-SA-DX5-resistant cells. It should be noted that parental MES-SA cells are more than 200 times more sensitive to doxorubicin compared to resistant cells.

Since these compounds have a moderate effect against cancer cell lines, it can be deduced that they should possess an inherent cytotoxicity. On the other hand, they also have a pronounced P-gp inhibitory effect (Figure 2). Indeed, the combination of these two biological properties may lead to an additive effect in resistant cells. In other words, the P-gp inhibitory activity contributes to the retention of the derivatives within the cell, where they can better exert their antiproliferative action.

The effect of the active compounds was also tested against HEK-293 non-cancerous cell line. Compounds A2, A3, A5, B2, B3, and B5 were derivatives with $\mathrm{IC}_{50}$ values higher than $50 \mu \mathrm{M}$ in these normal cells. Putting together all MTT results, it can be concluded that compounds A2 and $\mathbf{B} 2$ are the 
most promising agents, which show relative selectivity of action against resistant cells compared to non-resistant and also non-cancerous cell lines.

\subsubsection{Structure-Activity Relationships}

Considering the MDR reversal and cytotoxicity results, the following structure-activity relationships could be construed for the synthesized compounds:

\subsubsection{Comparison between 1,4-Dihydropyridine and Pyridine Structures}

The findings in MES-DX-5 drug resistant cells indicated that oxidation of 1,4-dihydropyridine ring in $\mathbf{A}$ (hexahydroquinoline) compounds could not significantly alter the MDR reversal effect of derivatives as compared with $\mathbf{B}$ (tetrahydroquinoline) series. As it can be observed in Figures 1 and 2 , A compounds show only a slight overall superiority over $\mathbf{B}$ agents. Both groups of hexahydroquinoline and tetrahydroquinoline derivatives in general demonstrated weak to moderate cytotoxic effects against MES-SA-DX5 cells in the MTT assay (Table 3).

On the other hand, oxidation of 1,4-dihydropyridine ring to pyridine counterpart resulted in an increase of the cytotoxic potential of compounds against $\mathrm{K} 562$ cells in most cases; e.g., $\mathbf{B 1}\left(\mathrm{IC}_{50}=\right.$ $6.7 \mu \mathrm{M}), \mathbf{B} 2\left(\mathrm{IC}_{50}=10.1 \mu \mathrm{M}\right)$ and $\mathbf{B} 5\left(\mathrm{IC}_{50}=10.4 \mu \mathrm{M}\right)$ demonstrated superior activity compared to their pyridine counterparts.

\subsubsection{Influence of the Substituted Group at $C_{4}$ Position of the Phenyl Ring}

The MDR reversal results indicated that most of the compounds bearing halogen moieties including $\mathrm{Cl}$ (A1, A3, A5, B1, B5) and $\mathrm{Br}$ (A2 and B2) on the phenyl ring showed superior MDR reversal effect compared to the compounds bearing other substitutes, such as methoxy, methyl, and hydroxyl, in both $\mathbf{A}$ and $\mathbf{B}$ series.

As for the cytotoxic effect, the findings showed that the best compounds especially against K562 cells were those bearing halogen moieties on the para position of phenyl ring (A1, A2, B1, B2) compared to compounds bearing other substitutes in both $\mathbf{A}$ and $\mathbf{B}$ series. It should also be mentioned that meta-chlorinated derivatives (A3 and B3) demonstrated weaker cytotoxic activity in cell lines compared to para-chlorinated counterparts (A5 and B5).

\section{Conclusions}

A series of 2-methyl-N-(2-methylthiazol-4-yl)-5-oxo-1,4,5,6,7,8-hexahydroquinoline-3-carboxamide derivatives (A series) and their tetrahydroquinoline analogs (B series) were synthetized and evaluated for MDR reversal and cytotoxic properties. Examination of MDR reversal in MES-SA-DX5 drug resistant cells by flow cytometric detection of Rh123 showed that compounds especially those bearing $\mathrm{Cl}$ and $\mathrm{Br}$ moieties in both hexahydroquinoline and tetrahydroquinoline subgroups are able to reverse MDR in a dose dependent manner. The flow cytometric analysis of cell cycle distribution in MES-SA-DX5 cells after treatment with some of the synthesized compounds showed that especially compounds A1 and A2 with 5-oxo-hexahydroquinoline structure bearing 2,4-dichlorophenyl and 4-bromophenyl moieties, respectively, and their tetrahydroquinoline counterparts B1 and B2 induce apoptosis in MDR cells. Compounds A2 and B2 did not show any effect against parental non-resistant MES-SA cells and had higher IC $_{50}$ values against HEK-293 non-cancerous cells compared to cancer cells. The results of this report show that the synthesized derivatives deserve further studies for discovery of novel MDR reversal agents.

Supplementary Materials: Chemical characterization data $\left({ }^{1} \mathrm{H}\right.$ NMR, ${ }^{13} \mathrm{C}$ NMR, Mass and IR spectra) of synthesized compounds A1-A8 and B1-B8 are available online, Tables S1-S64.

Author Contributions: Conceptualization, M.K., N.E. and O.F.; methodology, O.S., M.K., N.E. and O.F.; software, O.S., N.E. and O.F.; validation, M.K., N.E. and O.F.; formal analysis, O.S., M.D., M.M and M.T.; investigation, O.S., M.D., M.M and M.T.; resources, L.S., N.E. and O.F.; data curation, O.S., M.M and M.T.; writing-original draft preparation, O.S., M.D., M.T., M.M.; writing—review and editing, M.K., L.S., N.E., O.F.; visualization, O.S., M.D., 
M.M and M.T.; supervision, M.K., N.E. and O.F.; project administration, M.K., N.E. and O.F.; funding acquisition, M.K., L.S. and O.F. All authors have read and agreed to the published version of the manuscript.

Funding: This research was funded by National Institute for Medical Research Development (NIMAD), Tehran, Iran, grant number 943656 and also the Shiraz University of Medical Sciences, Vice Chancellor for Research, Shiraz, Iran.

Acknowledgments: Part of this study was performed within the Pharm. D. thesis of Mojtaba Dehghani at Shiraz University of Medical Sciences.

Conflicts of Interest: The authors declare no conflict of interest.

\section{Abbreviations:}

P-gp, P-glycoprotein; MDR, multidrug resistance; ABC, ATP binding cassette; Rh123, Rhodamine 123; DMSO, dimethylsulfoxide; TLC, thin layer chromatography; MTT, 3-(4,5-dimethylthiazolyl-2)-2,5-diphenyltetrazolium bromide reagent; DHPs, dihydropyridines

\section{References}

1. Fitzmaurice, C.; Akinyemiju, T.F.; Al Lami, F.H.; Alam, T.; Alizadeh-Navaei, R.; Allen, C.; Alsharif, U.; Alvis-Guzman, N.; Amini, E.; Anderson, B.O.; et al. Global, Regional, and National Cancer Incidence, Mortality, Years of Life Lost, Years Lived with Disability, and Disability-Adjusted Life-Years for 29 Cancer Groups, 1990 to 2016: A Systematic Analysis for the Global Burden of Disease Study. JAMA Oncol. 2018, 4, 1553-1568. [PubMed]

2. Gottesman, M.M.; Fojo, T.; Bates, S.E. Multidrug resistance in cancer: Role of ATP-dependent transporters. Nat. Rev. Cancer. 2002, 2, 48. [CrossRef] [PubMed]

3. Robey, R.W.; Pluchino, K.M.; Hall, M.D.; Fojo, A.T.; Bates, S.E.; Gottesman, M.M. Revisiting the role of ABC transporters in multidrug-resistant cancer. Nat. Rev. Cancer. 2018, 18, 452-464. [CrossRef] [PubMed]

4. Breier, A.; Gibalova, L.; Seres, M.; Barancik, M.; Sulova, Z. New insight into p-glycoprotein as a drug target. Anticancer Agents Med Chem. 2013, 13, 159-170. [CrossRef]

5. Juliano, R.L.; Ling, V. A surface glycoprotein modulating drug permeability in Chinese hamster ovary cell mutants. Biochimica et Biophysica Acta (BBA)-Biomembranes 1976, 455, 152-162. [CrossRef]

6. Teodori, E.; Dei, S.; Martelli, C.; Scapecchi, S.; Gualtieri, F. The functions and structure of ABC transporters: Implications for the design of new inhibitors of Pgp and MRP1 to control multidrug resistance (MDR). Curr. Drug Targets 2006, 7, 893-909. [CrossRef]

7. Li, X.; Yuan, H.; Wu, J.; Li, J.; Qu, X.; Xu, W.; Tang, W. Strategies to overcome or circumvent P-glycoprotein mediated multidrug resistance. Curr. Med. Chem. 2008, 15, 470-476. [CrossRef]

8. Kuppens, I.E.; Witteveen, E.O.; Jewell, R.C.; Radema, S.A.; Paul, E.M.; Mangum, S.G.; Beijnen, J.H.; Voest, E.E.; Schellens, J.H. A phase I, randomized, open-label, parallel-cohort, dose-finding study of elacridar (GF120918) and oral topotecan in cancer patients. Clin. Cancer Res. 2007, 13, 3276-3285. [CrossRef]

9. Robey, R.W.; Pluchino, K.M.; Hall, M.D.; Fojo, A.T.; Bates, S.E.; Gottesman, M.M. Inhibition of P-glycoprotein (ABCB1)-and multidrug resistance-associated protein 1 (ABCC1)-mediated transport by the orally administered inhibitor, CBT-1 ${ }^{\circledR}$. Biochem. Pharmacol. 2008, 75, 1302-1312. [CrossRef]

10. Miri, R.; Javidnia, K.; Mirkhani, H.; Hemmateenejad, B.; Sepeher, Z.; Zalpour, M.; Behzad, T.; Khoshneviszadeh, M.; Edraki, N.; Mehdipour, A.R. Synthesis, QSAR and calcium channel modulator activity of new hexahydroquinoline derivatives containing nitroimidazole. Chem. Biol. Drug Des. 2007, 70, 329-336. [CrossRef]

11. Miri, R.; Javidnia, K.; Sarkarzadeh, H.; Hemmateenejad, B. Synthesis, study of 3D structures, and pharmacological activities of lipophilic nitroimidazolyl-1, 4-dihydropyridines as calcium channel antagonist. Bioorg. Med. Chem. 2006, 14, 4842-4849. [CrossRef] [PubMed]

12. Edraki, N.; Mehdipour, A.R.; Khoshneviszadeh, M.; Miri, R. Dihydropyridines: Evaluation of their current and future pharmacological applications. Drug Discov. Today 2009, 14, 1058-1066. [CrossRef] [PubMed]

13. Tomassoni, D.; Lanari, A.; Silvestrelli, G.; Traini, E.; Amenta, F. Nimodipine and its use in cerebrovascular disease: Evidence from recent preclinical and controlled clinical studies. Clin. Exp. Hypertens 2008, 30, 744-766. [CrossRef] [PubMed]

14. Khedkar, S.A.; Auti, P.B. 1,4-Dihydropyridines: A class of pharmacologically important molecules. Mini Rev. Med. Chem. 2014, 14, 282-390. [CrossRef] 
15. Viradiya, D.; Mirza, S.; Shaikh, F.; Kakadiya, R.; Rathod, A.; Jain, N.; Rawal, R.; Shah, A. Design and Synthesis of 1,4-dihydropyridine Derivatives as Anti-Cancer Agent. Anticancer Agents Med. Chem. 2017, 17, 1003-1013. [CrossRef]

16. Steiger, S.A.; Li, C.; Backos, D.S.; Reigan, P.; Natale, N. Dimeric isoxazolyl-1, 4-dihydropyridines have enhanced binding at the multi-drug resistance transporter. Bioorg. Med. Chem. 2017, 25, 3223-3234. [CrossRef]

17. Krauze, A.; Grinberga, S.; Krasnova, L.; Adlere, I.; Sokolova, E.; Domracheva, I.; Shestakova, I.; Andzans, Z.; Duburs, G. Thieno [2, 3-b] pyridines-a new class of multidrug resistance (MDR) modulators. Bioorg. Med. Chem. 2014, 22, 5860-5870. [CrossRef]

18. Shekari, F.; Sadeghpour, H.; Javidnia, K.; Saso, L.; Nazari, F.; Firuzi, O.; Miri, R. Cytotoxic and multidrug resistance reversal activities of novel 1, 4-dihydropyridines against human cancer cells. Eur. J. Pharmacol. 2015, 746, 233-244. [CrossRef]

19. Radadiya, A.; Khedkar, V.; Bavishi, A.; Vala, H.; Thakrar, S.; Bhavsar, D.; Shah, A.; Coutinho, E. Synthesis and 3D-QSAR study of 1, 4-dihydropyridine derivatives as MDR cancer reverters. Eur. J. Med. Chem. 2014, 74, 375-387. [CrossRef]

20. Ranjbar, S.; Firuzi, O.; Edraki, N.; Shahraki, O.; Saso, L.; Khoshneviszadeh, M.; Miri, R. Tetrahydroquinolinone derivatives as potent P-glycoprotein inhibitors: Design, synthesis, biological evaluation and molecular docking analysis. MedChem Comm 2017, 8, 1919-1933. [CrossRef]

21. Firuzi, O.; Javidnia, K.; Mansourabadi, E.; Saso, L.; Mehdipour, A.R.; Miri, R. Reversal of multidrug resistance in cancer cells by novel asymmetrical 1,4-dihydropyridines. Arch. Pharm. Res. 2013, 36, 1392-1402. [CrossRef]

22. Shahraki, O.; Edraki, N.; Khoshneviszadeh, M.; Zargari, F.; Ranjbar, S.; Saso, L.; Firuzi, O.; Miri, R. Novel 5-oxo-hexahydroquinoline derivatives: Design, synthesis, in vitro P-glycoprotein-mediated multidrug resistance reversal profile and molecular dynamics simulation study. Drug Des. Dev. Ther. 2017, 11, 407. [CrossRef] [PubMed]

23. Ranjbar, S.; Khonkarn, R.; Moreno, A.; Baubichon-Cortay, H.; Miri, R.; Khoshneviszadeh, M.; Saso, L.; Edraki, N.; Falson, P.; Firuzi, O. 5-Oxo-hexahydroquinoline derivatives as modulators of P-gp, MRP1 and BCRP transporters to overcome multidrug resistance in cancer cells. Toxicol. Appl. Pharmacol. 2019, 362, 136-149. [CrossRef] [PubMed]

24. Gaspar, A.; Mohabbati, M.; Cagide, F.; Razzaghi-Asl, N.; Miri, R.; Firuzi, O.; Borges, F. Searching for new cytotoxic agents based on chromen-4-one and chromane-2,4-dione scaffolds. Res. Pharm. Sci. 2019, 14, 74-83. [PubMed]

Sample Availability: Samples of the compounds are available from the authors.

(C) 2020 by the authors. Licensee MDPI, Basel, Switzerland. This article is an open access article distributed under the terms and conditions of the Creative Commons Attribution (CC BY) license (http://creativecommons.org/licenses/by/4.0/). 